\title{
Methods for the estimation of loss of life due to floods: a literature review and a proposal for a new method
}

\author{
S. N. Jonkman · J. K. Vrijling • A. C. W. M. Vrouwenvelder
}

Received: 12 August 2007/ Accepted: 25 October 2007/Published online: 16 April 2008

(C) The Author(s) 2008

\begin{abstract}
This article deals with methods for the estimation of loss of life due to flooding. These methods can be used to assess the flood risks and to identify mitigation strategies. The first part of this article contains a comprehensive review of existing literature. Methods have been developed for different types of floods in different regions. In general these methods relate the loss of life in the flooded area to the flood characteristics and the possibilities for evacuation and shelter. An evaluation showed that many of the existing methods do not take into account all of the most relevant determinants of loss of life and that they are often to a limited extent based on empirical data of historical flood events. In the second part of the article, a new method is proposed for the estimation of loss of life caused by the flooding of low-lying areas protected by flood defences. An estimate of the loss of life due to a flood event can be given based on: (1) information regarding the flood characteristics, (2) an analysis of the exposed population and evacuation, and (3) an estimate of the mortality amongst the exposed population. By analysing empirical information from historical floods, new mortality functions have been developed. These relate the mortality amongst the exposed population to the flood characteristics. Comparison of the outcomes of the proposed method with information from historical flood events shows that it gives an accurate approximation of the number of observed fatalities during these events. The method is applied to assess the consequences for a largescale flooding of the area of South Holland, in the Netherlands. It is estimated that the analysed coastal flood scenario can lead to approximately 3,200 fatalities in this area.
\end{abstract}

S. N. Jonkman $(\bowtie) \cdot$ J. K. Vrijling $\cdot$ A. C. W. M. Vrouwenvelder Section of Hydraulic Engineering, Faculty of Civil Engineering and Geosciences, Delft University, Stevinweg 1, 2628 CN Delft, The Netherlands

e-mail: s.n.jonkman@tudelft.nl

\section{S. N. Jonkman}

Coastal and rivers division, Royal Haskoning, PO Box 8520, 3009 AM Rotterdam, The Netherlands

J. K. Vrijling

e-mail: j.k.vrijling@tudelft.nl

A. C. W. M. Vrouwenvelder

TNO Built Environment and Geosciences, van Mourik Broekmanweg 6, 2628 XE Delft, The Netherlands e-mail: ton.vrouwenvelder@tno.nl 
Keywords Loss of life - Floods · Mortality · Models · Consequences ·

Risk assessment

\section{Introduction}

Every year floods cause enormous damage and loss of life on a global scale. An analysis of global statistics showed that inland floods (river floods, flash floods and drainage floods) caused 175,000 fatalities and affected more than 2.2 billion people between 1975 and 2002 (Jonkman 2005). In these statistics the consequences of other types of floods such as coastal floods and tsunamis are not included. Table 1 gives an overview of some historical coastal floods to indicate the impacts of these events. These results show that coastal flood events are even more catastrophic than inland floods in terms of loss of life. A recent example of such a catastrophic event is the flooding caused hurricane Katrina in the year 2005. This event caused more than 1,100 fatalities in the state of Louisiana and hundreds of fatalities occurred in the flooded parts of the city of New Orleans. Other types of floods can also lead to large loss of life. The estimated death toll from the Indian Ocean tsunami in the year 2004 is approximately 230,000, making it one of the most catastrophic disasters in history.

Existing literature treats different aspects of the loss of life due to flooding. Some studies investigate loss of life patterns on global scale (Berz et al. 2001; Jonkman 2005) or discuss loss of life in the context of general public health impacts (Hajat et al. 2003; Ahern et al. 2005). Other studies focus on the analysis of the causes and circumstances of individual flood disaster deaths for specific regions or events (Coates 1999; Jonkman and Kelman 2005). This article focuses on methods for the estimation of loss of life due to flooding. These methods are generally used to identify the possible consequences of flooding, and results can be used to assess the flood risks and to identify mitigation strategies. The background of this article is a research program on flood risks in the Netherlands (van Manen and Brinkhuis 2005; Rijkswaterstaat 2006), in which the probabilities of and consequences of large-scale floods in the Netherlands have been assessed. In the research program it was recognized there was limited insight in the loss of life caused by flooding and no uniformly established method was available.

Therefore, the first objective of this article is to provide a comprehensive review of methods for the estimation of loss of life due to flooding. A review of literature has been conducted to identify methods used in different countries and for different types of flooding (coastal flooding, river flooding, but also tsunami-induced flooding). Different

Table 1 Overview of some historical coastal flood events

\begin{tabular}{llrl}
\hline Date & Affected area & Loss of life & Source \\
\hline $1-2-1953$ & Southwest of the Netherlands & 1,835 & Waarts (1992) \\
$1-2-1953$ & United Kingdom, East Coast & 315 & Kelman (2003) \\
$26-9-1959$ & Ise Bay, Japan & 5,101 & Tsuchiya and Yasuda (1980) \\
$30-4-1991$ & Bangladesh & $139,000^{\mathrm{a}}$ & Chowdhury et al. (1993) \\
$29-8-2005$ & New Orleans, United States & $1,118^{\mathrm{b}}$ & IPET (2007) \\
\hline
\end{tabular}

a According to Chowdhury et al. (1993) the estimated death toll for this event varies between 67,000 and 139,000

b Loss of life in the state of Louisiana. Additional fatalities occurred in other states, such as Mississippi and Florida 
methods have been identified by means of an extensive search in peer-reviewed literature and research reports. Given the background of this study (see above), it is evaluated whether the existing methods are applicable to assess the consequences of large-scale floods in the Netherlands.

The second objective is to develop a method for the estimation of loss of life caused by large-scale flooding of low-lying areas with a specific emphasis on the situation in the Netherlands. Large parts of the Netherlands are below sea level and the high water levels in the rivers (see Fig. 1). Flooding of these low-lying areas can occur due to breaching of flood defences and these events can flood extensive areas up to large water depths with catastrophic consequences. For example, in the Netherlands coastal flooding caused 1,835 fatalities in the southwestern parts of the country in the year 1953. Such low-lying areas can also be found in many other parts of the world, particularly in the deltas of large rivers, such as the Mississippi (United States) and the Yangtze (China). The proposed method can therefore also be relevant for such areas.

This article is structured as follows. Section 2 gives an overview and evaluation of loss of life models. Section 3 contains a proposal for a new method for the estimation of loss of life caused by large-scale floods. The application of the method is demonstrated in a case study in Sect. 4. Concluding remarks are presented in Sect. 5.

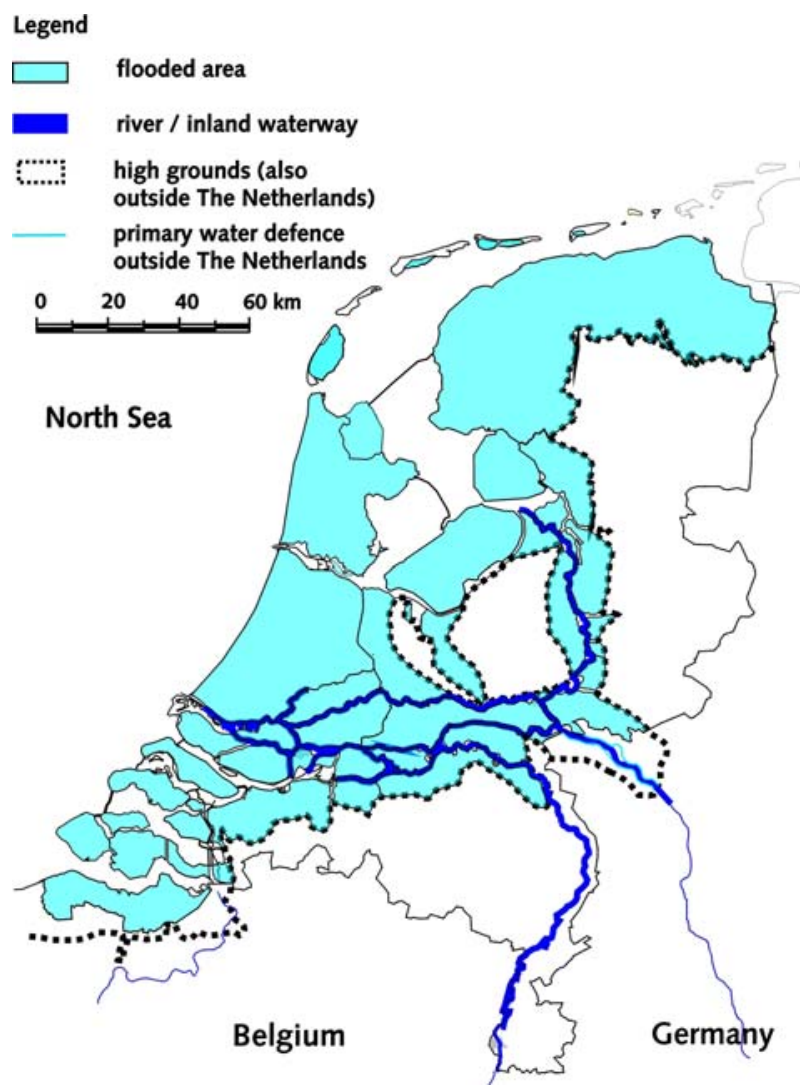

Fig. 1 Parts of the Netherlands that could potentially be flooded due to coastal and river flooding. Source: Rijkswaterstaat (2006) 


\section{A review of methods for the estimation of loss of life due to flooding}

In literature several methods have been developed that relate the mortality in a flooded area to flood characteristics and possibilities for warning and evacuation. Mortality is defined in this study as the number of fatalities divided by the number of exposed people. This section reviews the existing methods for the estimation of loss of life developed in several countries for different types of floods (Sect 2.1). Approaches for the analysis of human instability in flowing water are summarized in Sect. 2.2. The methods are evaluated in Sect. 2.3.

\subsection{Methods for the estimation of life due to different flood types}

In an international context, various methods have been developed for the estimation of loss life for different types of floods. The considered fields include dam breaks floods, tsunamis, coastal storm surges and river floods.

\subsubsection{Coastal storm surges}

On a global scale a large part of the loss of life due to flooding is caused by coastal flood events, such as storm surges and hurricanes/cyclones (see also Sect. 1).

Throughout history several large storm surges have struck Japan. Based on such historical events, Tsuchiya and Kawata (1981) derived a relationship between typhoon energy and mortality. These authors have also investigated the relationship between mortality and factors such as the collapse of buildings, the time of warning and the volume of flooding (i.e. flooded area multiplied by water depth). However, no definitive method for the prediction of mortality is proposed.

Mizutani (1985; quoted in Tachi personal communication) developed relationships for typhoons Jane and Isewan between average flood depth $(h)$ and mortality $\left(F_{\mathrm{D}}\right)$ :

Isewan typhoon:

$$
F_{\mathrm{D}}=10^{(2 / 3 \cdot h-11 / 3)} \quad F_{\mathrm{D}} \leq 1
$$

Typhoon Jane:

$$
F_{\mathrm{D}}=10^{(h-5.5)} \quad F_{\mathrm{D}} \leq 1
$$

Due to the large differences in mortality between the events (e.g. a factor 30 for water depth of $1 \mathrm{~m}$ ), it is believed that other factors, such as warning and the available time have played an important role.

Boyd (2005) analysed the loss of life in the city of New Orleans (USA) due to flooding after hurricane Betsy (September 1965). Fifty-one fatalities were directly related to the flooding of parts of the city. Based on the limited amount of available data, he proposed a linear relationship between mortality and storm surge height, $F_{\mathrm{D}}=0.304 \cdot 10^{-5} \mathrm{~h}$. In a later publication Boyd et al. (2005) derived a mortality function based on observations from seven flood events, including hurricanes Betsy (1965) and Camille (1969) in the United States. They proposed the following relationship between mortality and water depth (see Fig. 2):

$$
F_{\mathrm{D}}=\frac{0.34}{(1+\exp (20.37-6.18 h))}
$$


Fig. 2 Relationship between mortality and water depth based on observations from historical hurricane flood events (Boyd et al. 2005)

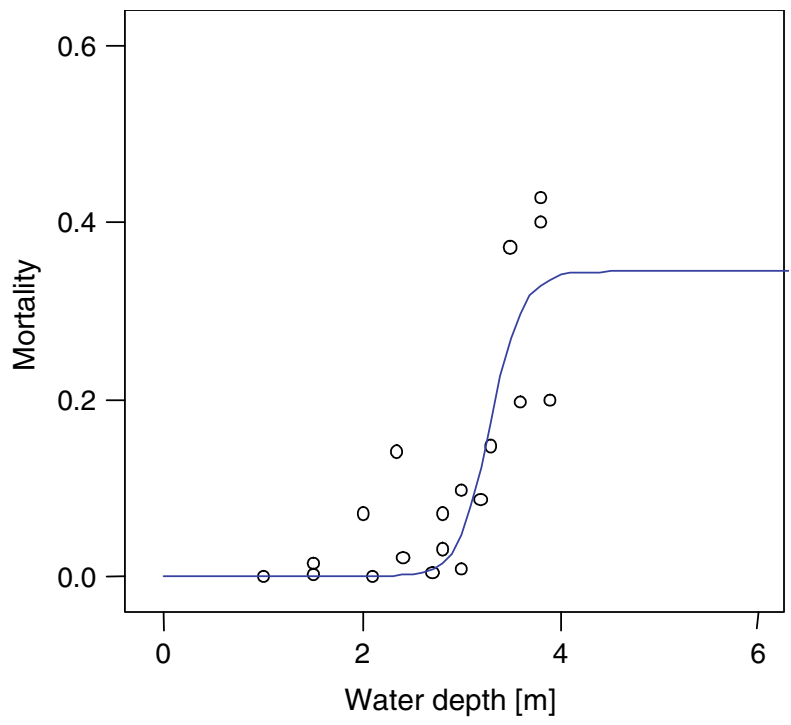

This function is $\mathrm{S}$-shaped and it has an asymptote for mortality $F_{\mathrm{D}}=0.34$ for water depth values that are approximately above $4 \mathrm{~m}$. This implies that about two thirds of the population will always survive regardless of the water depth. With respect to this asymptote for mortality the authors state: "One basic empirical fact of flood events is that there are always survivors. Rarely, if ever, has the entire population exposed to the flood perished. Instead, even if the water is extremely deep people tend to find debris, trees, attics, roofs, and other ways to stay alive. Only under the most extreme situations would one expect the fatality rate to reach one." (Boyd et al. 2005).

Following the catastrophic flooding of New Orleans after hurricane Katrina in August 2005, a method for the estimation of loss of life for hurricane-induced flooding of New Orleans has been developed in the context of the 'Interagency Performance Evaluation Taskforce' (IPET 2007). This method is based on the principles of the Lifesim model that has been developed by Utah State University for dam breaks (see Sect. 2.1.4), but now it is applied to flooding associated with breaching of flood defences. In the method in the IPET study, the exposed population is assigned to three different zones (walk away zone, safe zone, compromised zone). Each zone has a typical value for the mortality rate. Local flood depths and building heights and the age of the population ${ }^{1}$ determine the distribution of the population over the three zones. The number of people exposed has been distributed over the three zones so that the total number of observed fatalities was approximated well. The method can be used to assess the loss of life for hurricane related flood events in the greater New Orleans area, e.g. in the context of a risk analysis that includes future flood scenarios for the area.

\subsubsection{Methods developed in the Netherlands for coastal and river floods}

Large part of the Netherlands could be flooded both due to coastal and river flooding. Throughout the last decades several methods have been proposed in the Netherlands for the estimation of loss of life for coastal and river floods. Most methods are directly or

1 Because many of the fatalities due to the floods after hurricane Katrina were elderly, it is assumed in the IPET model that those over 65-year old are unable to evacuate vertically above the highest floor level. 
indirectly based on data on the fatalities caused by the 1953 flood disaster in the Netherlands. This event was induced by a storm surge on the North Sea that resulted in flooding in the Netherlands, the United Kingdom and Belgium. In the Netherlands large areas in the southwestern part of the country were flooded and the disaster caused enormous economic damage and 1835 fatalities. Duiser (1989) and Waarts (1992) collected data regarding the loss of life due to this disaster in the Netherlands from memorial volumes and official reports. Both reports give loss of life and hydraulic circumstances (water depth and sometimes rise rate) by municipality. Based on available descriptions, Waarts (1992) distinguished fatalities in three zones: a zone with high flow velocities, a zone with rapidly rising waters and a remaining zone. Table 2 presents the distribution of reported fatalities over the three categories and shows that most fatalities occurred in the zone with rapidly rising waters. This dataset has been used for the derivation of the methods described below.

Based on the available data, Duiser (1989) proposed a model that relates the local mortality fraction to the flood depth. More data on the 1953 floods have been added by Waarts (1992). He derived a general function for flood mortality $\left(F_{\mathrm{D}}[-]\right)$ as a function of water depth $(h[\mathrm{~m}])$ :

$$
F_{\mathrm{D}}(h)=0.665 \cdot 10^{-3} \mathrm{e}^{1.16 h} \quad F_{\mathrm{D}} \leq 1
$$

Waarts also proposed a more refined method that takes into account the effects of warning and evacuation, high flow velocities and the collapse of buildings. However, not all factors in this refined method have been specified based on historical data.

Based on Waarts' general functions, an extended method has been proposed by Vrouwenvelder and Steenhuis (1997). Especially rapidly rising floods will cause hazardous situations for people, and therefore the rate of rise of the water $(w[\mathrm{~m} / \mathrm{h}])$ is included in the mortality function (see also Fig. 3):

$$
\begin{aligned}
& F_{\mathrm{D}}=0 \quad h<3 \mathrm{~m} \quad \text { OR } \quad w<0.3 \mathrm{~m} / \mathrm{h} \\
& F_{\mathrm{D}}(h, w)=\min \left(\max \left(8.5 \mathrm{e}^{0.6 h-6}-0.15 ; 0\right) \cdot \min \left(\max \left(8.5 \mathrm{e}^{1.2 w-4.3}-0.15 ; 0\right), 1\right)\right) \\
& F_{\mathrm{D}}=1 \quad h>6.25 \mathrm{~m} \quad \text { AND } \quad w>2 \mathrm{~m} / \mathrm{h}
\end{aligned}
$$

It is noticeable that this function gives $F_{\mathrm{D}}=0$ for $h<3 \mathrm{~m}$. This is in contrast with the observations from the 1953 storm surge disasters, where about one third of the fatalities occurred at locations with water depths below $3 \mathrm{~m}$ (Jonkman 2007). For $w>2 \mathrm{~m} / \mathrm{h}$ and $h>3 \mathrm{~m}$ the function approximately corresponds to the above function of Waarts (1992), see Eq. 4.

Vrouwenvelder and Steenhuis (1997) proposed a method for sea and river floods. It takes into account the fraction of buildings collapsed $\left(F_{\mathrm{B}}\right)$, the fraction of fatalities near the breach $\left(F_{\mathrm{R}}\right)$, fatalities due to other factors $\left(F_{\mathrm{O}}\right)$ and the evacuated fraction of the affected

Table 2 Categorized data regarding fatalities caused by the 1953 disaster in the Netherlands, based on Waarts (1992)

\begin{tabular}{lcc}
\hline Zone & Fatalities & Fraction \\
\hline Rapidly rising waters & 1,047 & 0.58 \\
High flow velocities & 260 & 0.15 \\
Remaining zone & 488 & 0.27 \\
Total & $1,795^{\mathrm{a}}$ & 1 \\
\hline
\end{tabular}

${ }^{a}$ The difference between the totals 1,835 and 1,795 is accounted for by a number of people that died in a period after the disaster because of the illness and suffering they experienced during the first hours or days 


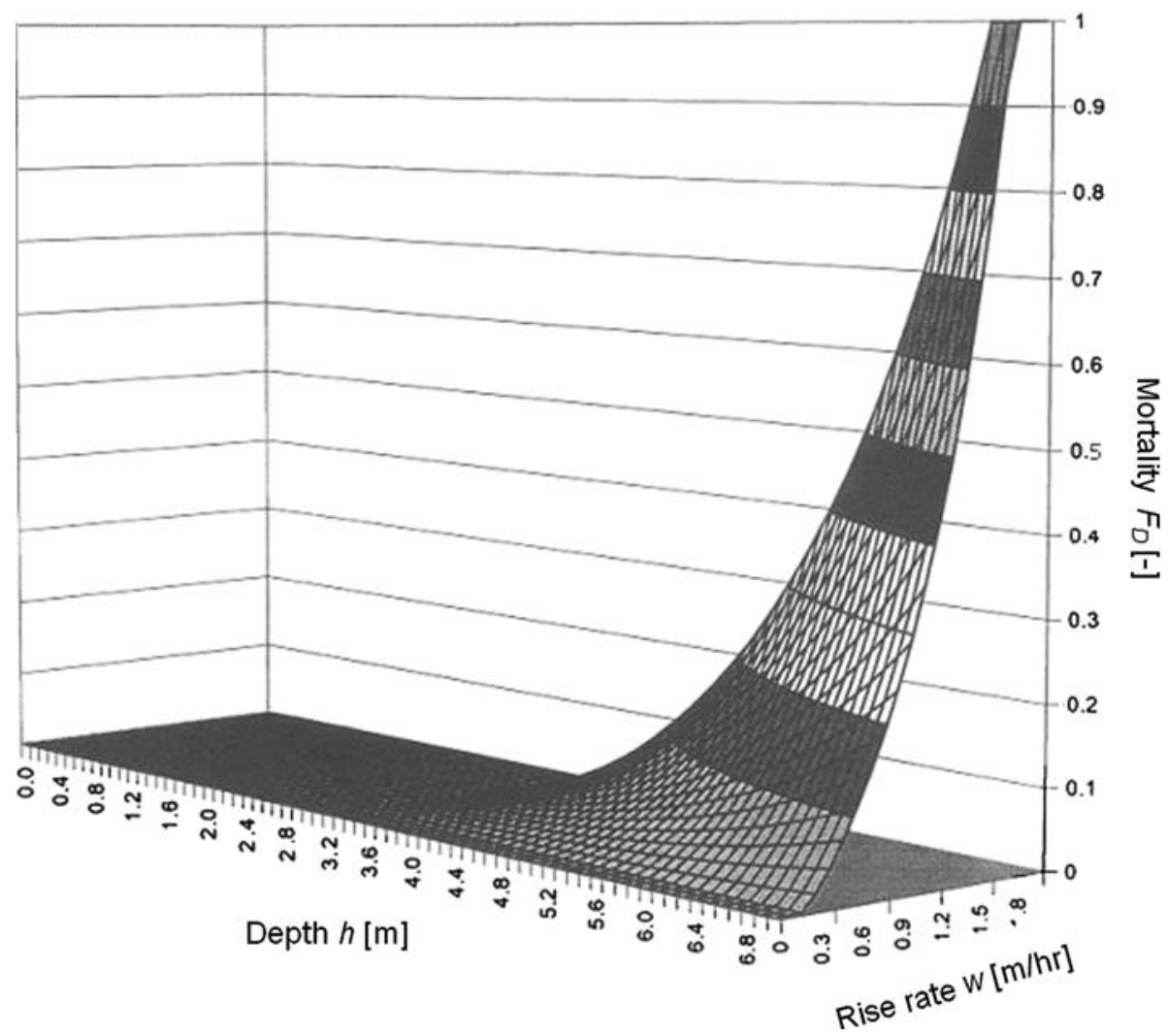

Fig. 3 Mortality as a function of water depth and rate of rise (Kok et al. 2002)

population $\left(F_{\mathrm{E}}\right)$. Combination with the number of inhabitants $\left(N_{\mathrm{PAR}}\right)$ yields the total number of fatalities $(N)$ :

$$
N=\left(F_{\mathrm{O}}+P_{\mathrm{B}} F_{\mathrm{R}}+P_{\mathrm{S}} F_{\mathrm{B}}\right)\left(1-F_{\mathrm{E}}\right) N_{\mathrm{PAR}}
$$

where $P_{\mathrm{B}}$ is the probability of dike breach nearby a residential area [-] and $P_{\mathrm{s}}$ is the probability of storm (1 for a coastal flood, 0.05 for a river flood) [-].

Some of the factors in the above method, for example $F_{\mathrm{R}}$ and $F_{\mathrm{B}}$, are not specified based on historical data but derived from expert judgement. Nevertheless the approach includes several important factors that influence loss of life.

Jonkman (2001) proposes a method for the determination of loss of life for sea and river floods in the Netherlands. It accounts for the effects of water depth, flow velocity and the possibilities for evacuation. Based on the results from human stability tests in flood flows (Abt et al. 1989; see also Sect. 2.2), a function to account for the effects of high flow velocities is given. Mortality becomes a function of flow velocity $v[\mathrm{~m} / \mathrm{s}]$, leading to $F_{\mathrm{D}}(v)$. Mortality due to higher water depths is modelled with the general function of Waarts $\left(F_{\mathrm{D}}(h)\right.$, see Eq. 4). It is also assumed that drowning due to water depth and flow velocity are disjunct events. The probability of a successful evacuation or escape is assumed to be a function of the time available for evacuation. Event mortality can now be expressed as: 


$$
F_{\mathrm{D}}\left(h, v, T_{\mathrm{A}}\right)=\left(F_{\mathrm{D}}(h)+F_{\mathrm{D}}(v)\right)\left(1-F_{\mathrm{E}}\left(T_{\mathrm{A}}\right)\right) \quad 0 \leq F_{\mathrm{D}}\left(h, v, T_{\mathrm{A}}\right) \leq 1
$$

where $T_{\mathrm{A}}$ is the time available for evacuation $[\mathrm{h}]$ and $F_{\mathrm{E}}$ is the evacuated fraction of the exposed population $[-]$.

All the above methods are directly or indirectly based on findings from the 1953 storm surge. An evaluation of these methods (Jonkman 2004) showed the following. Comparison with the available observations regarding the loss of life caused by the 1953 storm surge showed that these methods did not give a good prediction of the observed number of fatalities. In several of these methods, variables are included that are based on expert judgement and not on empirical data.

\subsubsection{Other methods for coastal and river floods}

Some authors developed more general methods applicable to both river and coastal floods. Zhai et al. (2006) analysed data from floods in Japan. They derived a relationship between the number of inundated houses and the loss of life. In these floods fatalities mainly occurred when more than 1,000 buildings were inundated and then increased as a function of the number of inundated buildings. The obtained statistical relationships show considerable variation, which might be due to the influence of other factors such as warning, evacuation, flood characteristics and the actual collapse of buildings.

Ramsbottom et al. (2003, 2004), see also Penning-Rowsell et al. (2005), developed an approach for assessing the flood risk to people, in a research project for the Environment Agency for England and Wales. The risk to people is determined by three factors: flood hazard, people vulnerability and area vulnerability. A flood hazard rating is indirectly based on the available tests for human instability and the effects of debris. The proposed values for the other factors are based on expert judgement. By combination of these three factors, the numbers of fatalities and injuries are estimated. The method is applied to three case studies covering past river floods in the UK, and the obtained results agree well with the observed historical data.

In several countries methods are available to identify hazard zones for different types flooding. These methods provide a qualitative indication of the hazard (high, moderate, low) based on the combination of water depth and flow velocity that could be expected during a flood. Criteria have been developed to determine the risks to people and the risk of building collapse. These criteria are based on available information related to instability of people and building collapse in flowing water (see also Sect. 2.2 for further elaboration). Examples of such applications are a study on hazard classification for river flooding in New Zealand (Wood 2007) and the guidelines for hazard classification for dam break floods in the United States (USBR 1988).

\subsubsection{Dam break floods}

McClelland and Bowles (2002) give a comprehensive historical review of loss of life methods for dam break floods and also discuss their merits and limitations. Here, the most important methods are summarized.

Brown and Graham (1988) developed a function to estimate the number of fatalities $(N)$ for dam breaks as a function of the time available for evacuation ${ }^{2}\left(T_{\mathrm{A}}\right)$ and the size of the population at risk $\left(N_{\mathrm{PAR}}\right)$ :

\footnotetext{
${ }^{2}$ In the original publications this variable is indicated as warning time.
} 


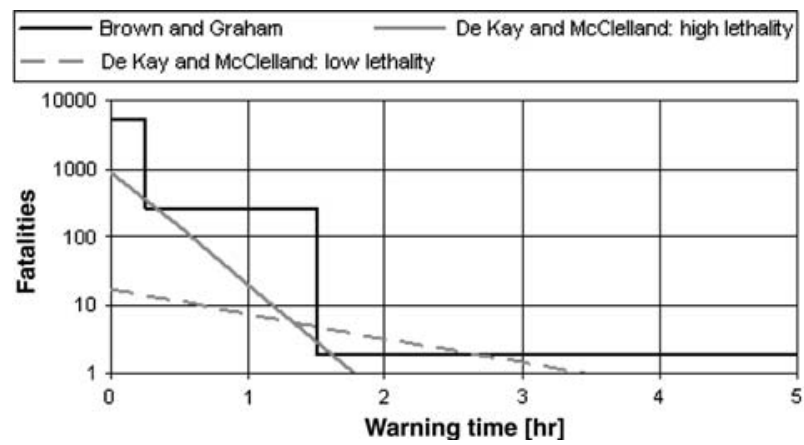

Fig. 4 Estimated number of fatalities for dam break as a function of warning time for a population of $N_{\text {PAR }}=10,000$ according to the methods of Brown and Graham (1988) and DeKay and McClelland (1993). Note that the vertical axis is depicted on a logarithmic scale

$$
\begin{aligned}
& N=0.5 N_{\mathrm{PAR}} \quad T_{\mathrm{A}}<0.25 \mathrm{~h} \\
& N=N_{\mathrm{PAR}}^{0.6} \quad 0.25<T_{\mathrm{A}}<1.5 \mathrm{~h} \\
& N=0.0002 N_{\mathrm{PAR}} \quad T_{\mathrm{A}}>1.5 \mathrm{~h}
\end{aligned}
$$

The procedure is derived from the analysis of 24 major dam failures and flash floods. The formulas show large discontinuities. For example for $N_{\mathrm{PAR}}=10,000$ the loss of life jumps from 5,000 to 251 at $T_{\mathrm{A}}=0.25 \mathrm{~h}$ and then jumps from 251 to 2 at $T_{\mathrm{A}}=1.5 \mathrm{~h}$ (see also Fig. 4).

DeKay and McClelland (1993) make a distinction between "high lethality" and "low lethality" floods. They define high lethality floods as events with large hydraulic forces, for example in canyons, where $20 \%$ of the flooded residences are either destroyed or heavily damaged. Low lethality conditions occur when less than $20 \%$ of the houses are destroyed or damages and these usually occur on flood plains. The following relationships, again a function of population size and time available for evacuation, have been proposed:

$$
\begin{aligned}
& N=N_{\text {PAR }}\left(1+5.207 N_{\text {PAR }}{ }^{0.513} \mathrm{e}^{\left(3.838 T_{\mathrm{A}}-4.012\right)}\right)^{-1} \text { for "high lethality" floods } \\
& N=N_{\text {PAR }}\left(1+5.207 N_{\text {PAR }}{ }^{0.513} \mathrm{e}^{\left(3.838 T_{\mathrm{A}}-4.012\right)}\right)^{-1} \quad \text { for "low lethality" floods }
\end{aligned}
$$

In both functions loss of life decreases very quickly when the time available increases (see Fig. 4). It is noted that re-ordering ${ }^{3}$ of both the above functions shows of the population at risk. Application of this expression for short warning times gives mortality values in the order $10^{-2}$ to $10^{-4}$.

3 For example, the DeKay and McClelland expression for mortality $\left(F_{\mathrm{D}}\right)$ in low lethality floods becomes:

$$
F_{\mathrm{D}}=N / N_{\mathrm{PAR}}=\left(1+5.207 N_{\mathrm{PAR}}^{0.513} \mathrm{e}^{0.822 T_{\mathrm{A}}}\right)^{-1}
$$


Graham (1999) presents a framework for estimation of loss of life due to dam failures. Recommended fatality rates are provided based on the severity of the flood, the amount of warning and the understanding of the flood severity by the population. Quantitative criteria for flood severity are given in the form of the water depth and the depth-velocity product. Three categories of warning time are distinguished: no/little warning $(<15 \mathrm{~min})$, some warning (15-60 $\mathrm{min})$ and adequate warning (>60 min). The understanding of the flood severity depends on whether a warning is received and understood by the population at risk. The recommended fatality rates are based on the analysis of 40 historical dam breaks. In later work Reiter (2001) introduced factors in Graham's approach to account for the vulnerability of the population (number of children and elderly), and the influence of warning efficiency and possible rescue actions.

The methods discussed above are based on statistical analyses of data from historical floods. Recent research has focused on more detailed simulation of flood conditions and individual behaviour of people after dam break floods. The 'Life Safety Model' developed by British Columbia Hydro (Watson et al. 2001; Assaf and Hartford 2002; Hartford and Baecher 2004; Johnstone et al. 2005) takes into account the hydraulic characteristics of the flood, the presence of people in the inundated area and the effectiveness of evacuation. An individual's fate is modelled mechanistically, i.e. individual behaviour causes of death are accounted for at an individual level. Drowning can occur in three different states: when the building in which a person stays is destroyed, when a walking person loses his stability or when a person's vehicle is overwhelmed by the water. Calculations result in different values for loss of life for different times of the year, week and day due to differences in affected population and the effectiveness of warning. As a validation, Johnstone et al. (2003, 2005) use the model for a reconstruction of the consequences of the Malpasset dam failure in France in 1959.

Utah State University (McClelland and Bowles 1999, 2002; Aboelata 2002) has developed a model ('Lifesim') for loss of life estimation for dam break floods. It considers several categories of variables to describe the flood and area characteristics, warning and evacuation and the population at risk. A comprehensive analysis of historical dam break cases and the factors determining loss of life has been undertaken (McClelland and Bowles 2002). Different flood zones are distinguished based on the characteristics of the flood (depth, velocity) and the availability of shelter. Mortalities observed in historical cases have differed distinctly between flood zones. In the most hazardous chance zones, historical mortalities range from $F_{\mathrm{D}}=0.5$ to 1 with an average of 0.9 . In compromised zones, where the available shelter has been severely damaged, the average death rate amounts to 0.1. The model has been implemented in a GIS framework and can be used for both deterministic (scenario) and probabilistic (risk analysis) calculations.

\subsubsection{Tsunamis}

A method for the estimation of loss of life due to tsunamis is given in CDMC (2003). Based on historical statistics from Japanese tsunamis, mortality is estimated as a function of tsunami wave height $\left(h_{\mathrm{ts}}[\mathrm{m}]\right)$ when it reaches land:

$$
F_{\mathrm{D}}=0.0282 \mathrm{e}^{0.2328 h_{\mathrm{ts}}} \quad F_{\mathrm{D}} \leq 1
$$

Correction factors are proposed which account for the tsunami arrival time and resident awareness, and thus for the effects of evacuation and warning. Furthermore the extent of dike and sea wall breaching is included in the mortality estimation. 
Sugimoto et al. (2003) and Koshimura et al. (2006) propose methods that combine a numerical simulation of the inundation flow due to tsunami and an analysis of the evacuation process. Both methods use criteria for human instability in flowing water (see Sect. 2.2) to estimate the loss of life.

After the Indian Ocean tsunami of December 2004, various publications have addressed the loss of life caused by this tragic event. Various surveys were conducted amongst affected households in different affected areas (Nishikiori et al. 2006; Rofi et al. 2006; Doocy et al. 2007; Guha-Sapir et al. 2007). It is striking that all these studies reported mortality fractions in the affected areas between $F_{\mathrm{D}}=0.129$ and $F_{\mathrm{D}}=0.17$. These investigations present very relevant information related to individual risk factors, such as age and gender. However, they do not directly address the relationship between mortality and the characteristics of the tsunami wave and the consequent inland flooding.

\subsection{Human instability in flowing water}

Although flood fatalities can occur due to various other causes such as physical trauma, heart attack and drowning in cars (Jonkman and Kelman 2005), loss of human stability and consequent drowning are a high personal hazard. Therefore several authors have investigated the issue of human (in)stability in flowing water. Most authors propose a critical depth-velocity $\left(h v_{\mathrm{c}}\right)$ product indicating the combination of depth $(h[\mathrm{~m}])$ and velocity $(v[\mathrm{~m} / \mathrm{s}])$ that would lead to a person's instability. Similarly, in analysing building collapse in flood flows, the $h v_{\mathrm{c}}$ product also tends to be used (e.g. Clausen 1989; Kelman 2002). Such criteria can be used for the creation of flood hazard maps for different types of flooding.

This topic's first experimental study was presumably (Abt et al. 1989), as they state that "previous work of this nature was not located in literature" (p. 881). They conducted a series of tests in which human subjects and a monolith were placed in a laboratory flume in order to determine the water velocity and depth which caused instability. Equation 11 was derived from the resulting empirical data to estimate the critical product $h v_{\mathrm{c}}$ at which a human subject becomes unstable as a function of the subject's height $(L[\mathrm{~m}])$ and mass $(m[\mathrm{~kg}])$ :

$$
h v_{\mathrm{c}}=0.0929\left(\mathrm{e}^{0.001906 L m+1.09}\right)^{2}
$$

Further tests on humans in laboratory flumes were carried out in the Rescdam project (Karvonen et al. 2000). Depending on the test person's height and mass, critical depthvelocity products were found between $0.64 \mathrm{~m}^{2} / \mathrm{s}$ and $1.29 \mathrm{~m}^{2} / \mathrm{s}$. Based on the test data, the authors proposed the following limit for manoeuvrability under normal conditions:

$$
h v_{\mathrm{c}}=0.004 \mathrm{Lm}+0.2
$$

In Japan, experiments were conducted on the feasibility of walking through floodwaters. Suetsugi (1998) reports these results in English indicating that people will experience difficulties in walking through water when the depth-velocity product exceeds $0.5 \mathrm{~m}^{2} / \mathrm{s}$.

Figure 5 shows the combinations of water depth and flow velocity that resulted in instability in the two experimental series, i.e. those by Abt et al. and Karvonen et al. The lines show combinations with a constant value of the depth-velocity product $(h v)$. The middle line has a value of $h v=1.35 \mathrm{~m}^{2} / \mathrm{s}$. This corresponds to the value that follows from the criterion proposed by Abt et al. (1989) for a person with $L=1.75 \mathrm{~m}$ and $m=75 \mathrm{~kg}$ (see Eq. 11). It is expected that this type of criterion can be used for conditions in which experiments were conducted, i.e. $0.5<v<3 \mathrm{~m} / \mathrm{s}$ and $0.3<h<1.5 \mathrm{~m}$. Figure 5 also 
Fig. 5 Combination of water depth and flow velocity that led to instability of test persons in the experiments by Abt et al. (1989) and Karvonen et al. (2000)

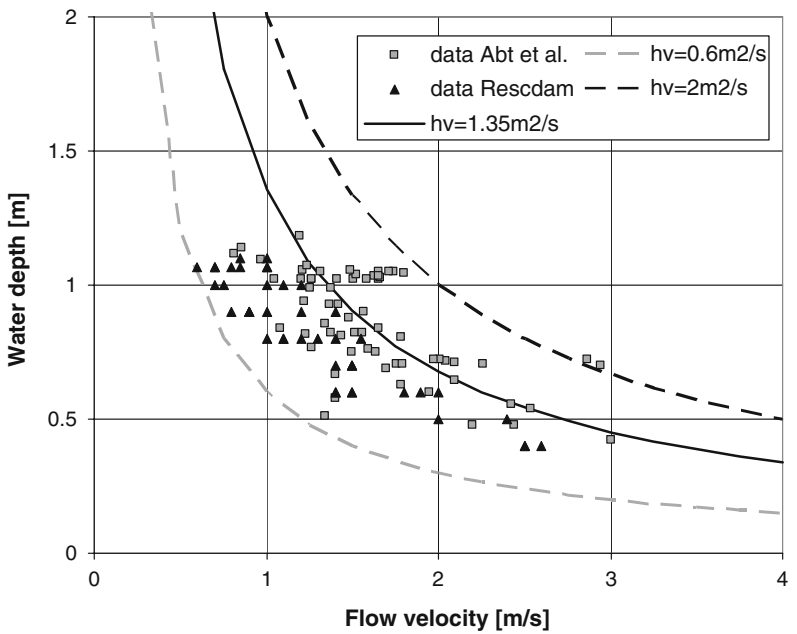

illustrates that the two datasets are different (see also Ramsbottom et al. 2004). This reflects that the two experiments were carried out under different test circumstances (bottom friction, test configuration) and involved a variety of personal characteristics (weight, height, clothing).

Different authors have used the available test data to derive empirical functions for determining stability. Lind and Hartford (2000), also see Lind et al. (2004), derived theoretical relationships for the stability in water flows of three shapes representing the human body: a circular cylindrical body, a square parallelepiped body, and composite cylinders (two small ones for the legs and one for the torso). Based on the developed relationships and calibration with test data, they proposed a reliability function that can be used the probability of instability for a given person under certain flow conditions. USBR (1988) and Green (2001) give semi-quantitative criteria that indicate certain hazard ranks (e.g. high and low danger zones) as a function of water depth and flow velocity. Similarly, Ramsbottom et al. (2004) and Penning-Rowsell et al. (2005) have proposed a semi-quantitative equation to relate the flood hazard to people to depth and velocity of the water as well as the amount of debris that is in the water. From this equation the level of hazard to people can be estimated and then categorized as 'low', 'moderate', 'significant' or 'extreme'.

Overall, the available studies show that people lose stability in flows in relatively low depth-velocity products. The obtained critical depth-velocity products for standing range from $0.6 \mathrm{~m}^{2} / \mathrm{s}$ to about $2 \mathrm{~m}^{2} / \mathrm{s}$. These two values are also indicated in Fig. 5. People may experience difficulties in wading through water at lower depth-velocity products. In practice several other phenomena could even reduce stability more, for example obstacles on the bottom or reduced fatigue of persons in the water.

\subsection{Discussion and evaluation of methods for loss of life estimation}

Despite the enormous impacts of floods on global scale, a limited number of methods is available for the estimation of loss of life due to flooding. The previous sections have given a review of (known) available methods and such a comprehensive overview was not available in literature so far. Below, the methods are briefly evaluated with respect to their field of application, and background data and modelling approach. Table 3 summarizes the 


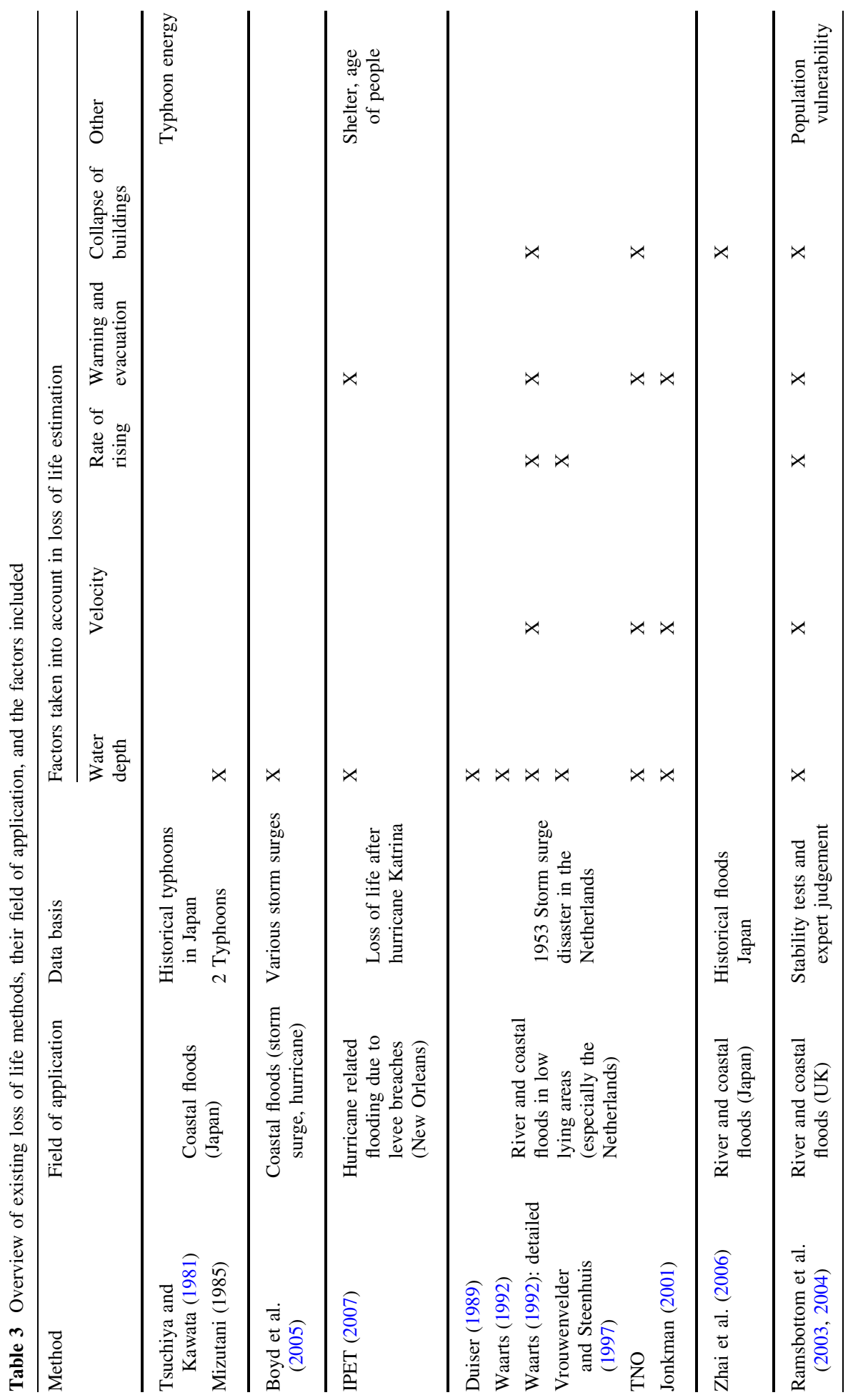




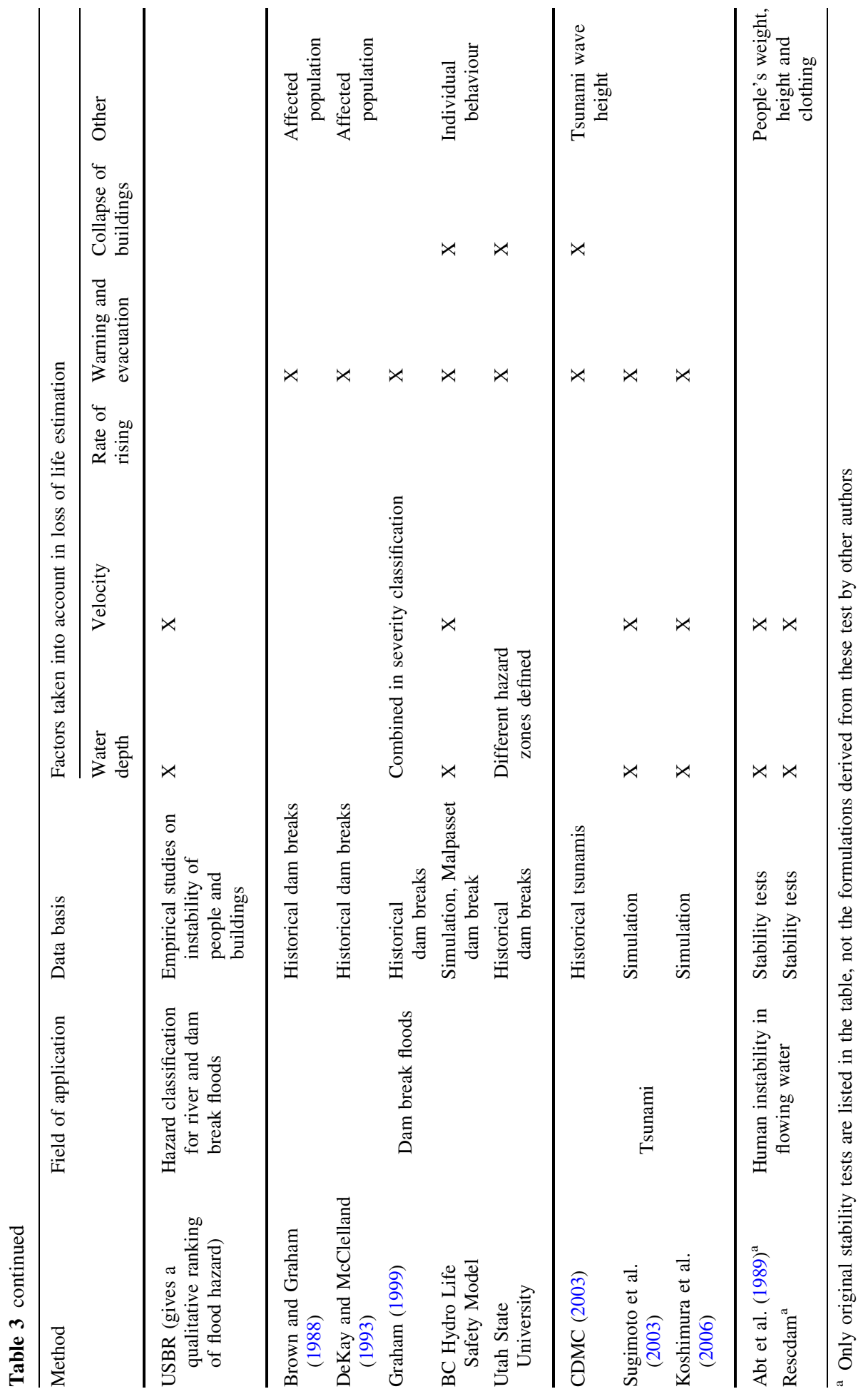


methods, their field of application and shows which factors are taken into account in loss of life estimation.

The methods have been developed for different types of floods in different regions. Applications that have received relatively much attention are dam breaks in USA and Canada, coastal storm surges in Japan, floods in the Netherlands, and human instability in flood flows. All of the reviewed methods include some kind of function which relates mortality to flood characteristics. Depending on the flood type and the type of area different variables will be most significant in predicting loss of life. For large-scale dam breaks, warning time is very important, as people exposed to the effects of a large dam break wave have limited survival chances. For coastal and river floods, local water depth and rate of rising are important parameters for mortality. For all floods evacuation is a critical factor in loss of life estimation, as it reduces the number of people exposed to the flood. It is noted that this factor is not included in many of the approaches listed in Table 3.

Figure 6 schematically compares some of the discussed methods with respect to their level of detail and modelling principles. The level of detail (vertical axis) varies from the modelling of each individual's fate to an overall estimate for the whole event. On the horizontal axis the basic modelling principles are categorized. Mechanistic methods are those that model the individual behaviour and the causes of death. Empirical methods relate mortality in the exposed population to event characteristics.

The methods of Utah State University and BC Hydro use detailed local data and capture the mechanisms that lead to mortality. The method of BC Hydro is most detailed as it simulates an individual's fate during a flood event. The disadvantage of such a mechanistic approach is that a large number of variables have to be assigned for which very limited empirical information is available, e.g. variables related to the behaviour of the person. Yet, detailed simulations can provide visualisation tools for communication with the public and decision makers. More empirically based methods have been proposed which take account of local circumstances (e.g. the methods of Ramsbottom et al. and Waarts) or give a purely empirical estimation of mortality for an event (e.g. the methods of Graham and DeKay and McClelland). In general the single-parameter methods (i.e. the methods that include one factor such as water depth or warning time) are fully based on historical data. Probably due to the lack of historical data, not all the factors in multi-parameter methods could be empirically derived.

One objective of this study was to investigate the applicability of the available methods for floods of low-lying areas protected by flood defences, with specific emphasis on the situation in the Netherlands. Many of the available methods have been specifically developed for other types of floods (e.g. dam breaks) and they are less suitable for the type of flood considered here. A group of methods have been developed for the situation in the

Fig. 6 Comparison of the proposed method with other methods for loss of life estimation (based on Johnstone et al. 2005)

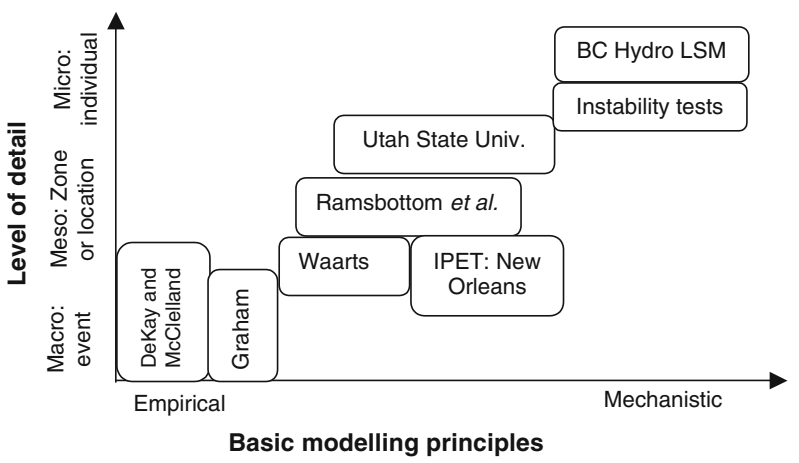


Netherlands (see Sect. 2.1.2) and these are largely based on observations regarding loss of life caused by the 1953 storm surge in the Netherlands. An evaluation of these methods (Jonkman 2004) showed that these methods did not give a good prediction of the observed number of fatalities in the 1953 flood. Overall, most of the existing methods do not take into account the combined influence of different factors that are considered to be the most relevant determinants of loss of life, e.g. water depth, rise rate, evacuation, collapse of buildings and shelter. In addition, most of the existing methods have a limited empirical basis and the influence of several variables is often estimated based on expert judgement. Given their different bases and natures, applying different loss of life methods will give different results. Application of some of the discussed methods to a region in the Netherlands with 360,000 inhabitants showed that the predicted loss of life varied between 72 and 88,000 (Jonkman et al. 2002).

Given the above considerations it is expected that the available methods are not able to provide an accurate estimate of loss of life for large-scale floods of low-lying areas in the Netherlands. Therefore, there is a need for the development a new method for the estimation of loss of life that takes into account the most relevant determinants. A first attempt to provide a modelling framework based on empirical information from historical flood events is presented in the next section.

\section{A new method for the estimation of loss of life due to flooding}

\subsection{Determinants of loss of life}

In order to develop a method for the estimation of loss of life, it is necessary to have insight in the factors that determine loss of life. To gain more insight in these determinants documents with relevant information from historical flood events have been examined. Given the scope of this study, the examined cases concern floods in low-lying areas protected by flood defences. Table 4 gives an overview of the events and the data sources, see Jonkman (2007) for further details.

Despite differences with respect to their temporal and geographical situation, the major factors that have determined the loss of life in these historical flood events seem to be similar. Based on the available information and previous analyses (e.g. Tsuchiya and Yasuda 1980; Bern et al. 1993; McClelland and Bowles 2002; Ramsbottom et al. 2003), the main factors that influence mortality are summarized below:

- The events with the largest loss of life occurred unexpectedly and without substantial warning. Many of the high-fatality events also occurred at night (Netherlands and UK 1953, Japan 1959), making notification and warning of the threatened population difficult.

- Timely warning and evacuation prove to be important factors in reducing the loss of life. Even if the time available is insufficient for evacuation, warnings can reduce the loss of life. Warned people may have time to find some form of shelter shortly before or during the flood.

- The possibilities for shelter are a very important determinant of mortality. Buildings can have an important function as a shelter, but possibilities to reach shelters will depend on the level of warning, water depth and rise rate of the water.

- The collapse of buildings in which people are sheltering is an important determinant of the number of fatalities. Findings from different events (Bangladesh 1991, Netherlands 


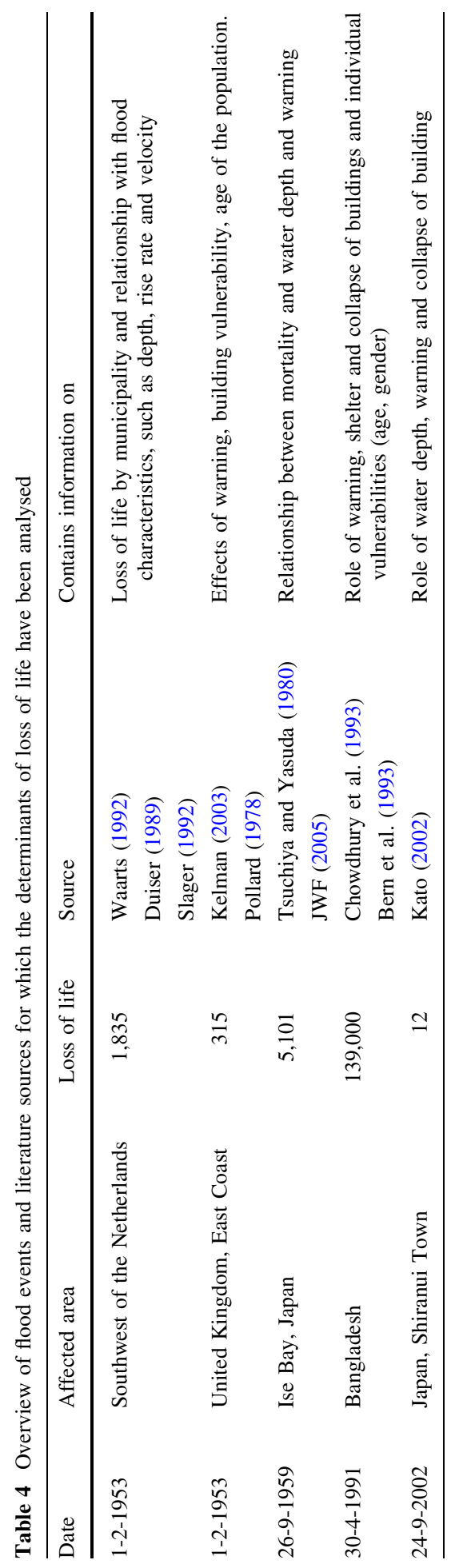


1953) show that most fatalities occurred in areas with vulnerable and low quality buildings.

- Water depth is an important parameter, as possibilities for shelter decrease with increasing water depth. Low-lying and densely populated areas, such as reclaimed areas or polders, will be most at risk.

- The combination of larger water depths and rapid rise of waters is especially hazardous. In these cases people have little time to reach higher floors and shelters and they may be trapped inside buildings.

- High flow velocities can lead to the collapse of buildings and instability of people. In different cases (Netherlands and UK 1953, Japan 1959), many fatalities occurred behind dike breaches and collapsed sea walls, as flow velocities in these zones are high.

- When exposed to a severe and unexpected flood, children and elderly were more vulnerable. This suggests that chances for survival are related to an individual's stamina and his or her ability to find shelter. A further analysis of individual vulnerabilities is provided in Jonkman and Kelman (2005).

The above factors are important determinants of the loss of life. Local variations in the above factors may lead to differences between mortality fractions for different locations within one flood event. Especially unfavourable combinations of the above factors will contribute to high mortality. For example in the 1953 floods in the Netherlands, mortality was highest at locations where (a) no flood warnings were given, (b) the waters rose rapidly to larger water depths, and (c) where the quality of buildings was poor.

\subsection{Proposed approach for loss of life estimation}

To estimate the loss of life caused by a flood event, it is proposed to take into account three general steps ${ }^{4}$ :

(1) Analysis of flood characteristics, such as water depth, rise rate and flow velocity;

(2) Estimation of the number of people exposed (including the effects of warning, evacuation and shelter);

(3) Assessment of the mortality amongst those exposed to the flood.

This approach can be used to assess the consequences of hypothetical but possible flood events, for example in the context of a risk analysis. Figure 7 schematically shows the general approach for the estimation of loss of life due to flooding. The analysis starts with the total number of people at risk before the event in the threatened area. By analysing the possibilities for evacuation, shelter and rescue, the total number of people exposed to the floodwaters $\left(N_{\mathrm{EXP}}\right)$ can be estimated. Consequently the mortality in the exposed population $\left(F_{\mathrm{D}}\right)$ can be estimated. Mortality is defined in this study as the number of fatalities divided by the number of exposed people. Mortality functions can be used that relate the mortality fraction to flood characteristics (e.g. water depth) and other important factors such as the collapse of buildings. The number of fatalities $(N)$ can be estimated as follows:

$$
N=F_{\mathrm{D}} N_{\mathrm{EXP}}
$$

In the analysis of these steps the different determinants of loss of life can be taken into account (see Sect. 3.1). For example in the analysis of the possibilities for evacuation of

\footnotetext{
${ }^{4}$ In a more general sense, similar steps can also be used to assess the loss of life for other natural and technological disasters (Jonkman 2007).
} 


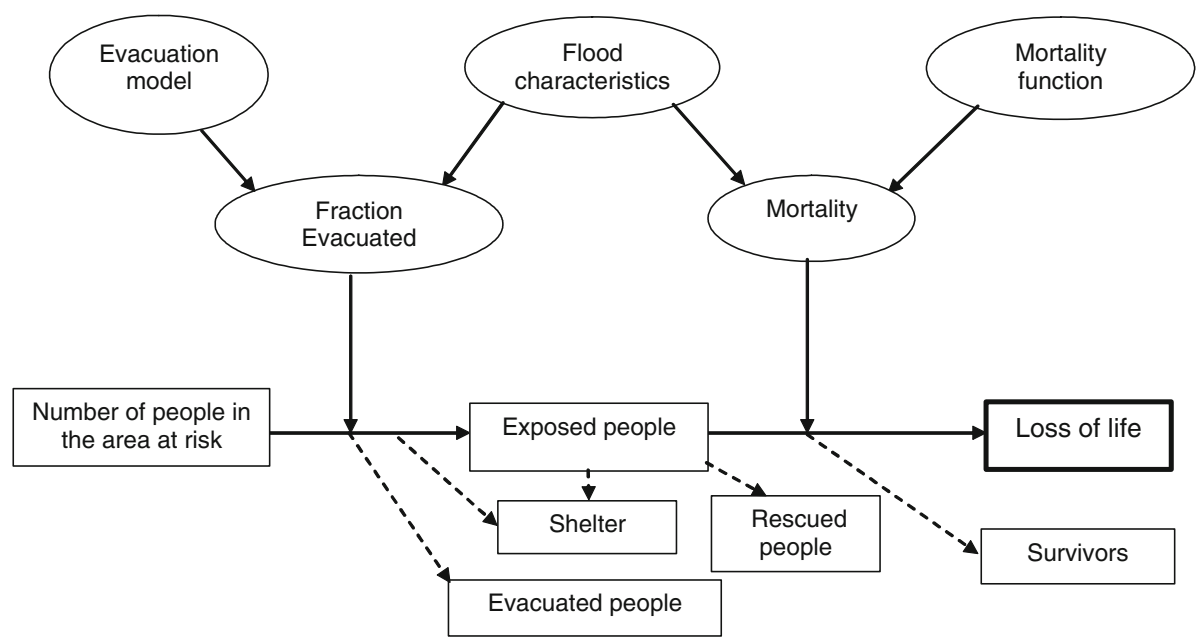

Fig. 7 General approach for the estimation of loss of life due to flooding

affected people, the effectiveness of warning can be taken into account. The following sections deal with the general steps in the above approach. Section 3.3 contains the simulation of flood characteristics. Section 3.4 describes the modelling of evacuation, shelter and rescue and the assessment of the number of people exposed. As previous work has already focussed on the analysis of these two steps, they are treated relatively briefly. Most emphasis is given to the development of mortality functions for floods in Sect. 3.5. Section 3.6 describes the validation of the method.

\subsection{Simulation of flood characteristics}

To assess the damage and loss of life due to a flood, it is necessary to have an understanding of its hydraulic characteristics. These are determined for a so-called flood scenario. A flood scenario refers to one breach or a set of multiple breaches in a flood defence system and the resulting pattern of flooding, including the flood characteristics. For each flood scenario the location of breaching, the outside hydraulic load conditions (river discharge, water level, waves) and the breach growth rate have to be determined. It is noted that the analysis of outside hydraulic boundary conditions is very important for a proper analysis of the course of flooding and the consequences. In the context of flood risk analysis also, the probability of a flood scenario has to be estimated.

The most relevant flood characteristics for loss of life estimation include: water depth, rise rate, flow velocity and arrival time of the water (see also Sect. 3.1). The rise rate of the water is expected to be an important determinant of loss of life as it influences the possibilities to find shelter on higher grounds or floors of buildings. The rise rate can be derived from the development of water depth over time. In the context of loss of life estimation, it is proposed to estimate the average rise rate at a location from the initiation of flooding up to a depth of $1.5 \mathrm{~m}$ (see Fig. 8). Then the water level approximates the human head level and becomes hazardous for people. This approach prevents finding very high rise rates over small incremental changes of water depth, for example over the first decimetres of water in Fig. 8. As the rise rate is averaged, it is indicated with symbol $w[\mathrm{~m} / \mathrm{h}]$. 
Fig. 8 Estimation of the (averaged) rise rate over the first $1.5 \mathrm{~m}$ of water depth

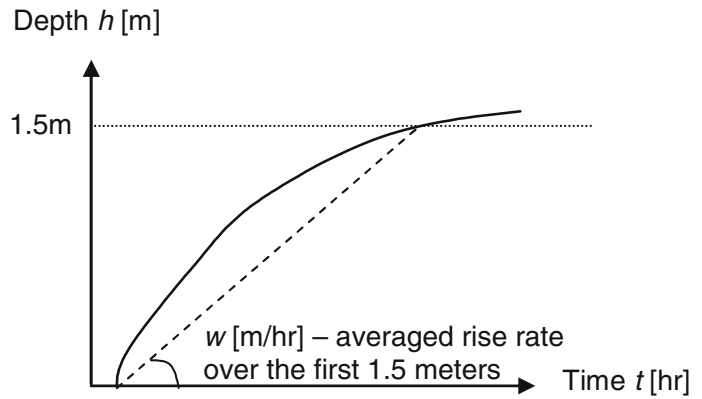

Information regarding the different flood characteristics can be obtained from flood simulations. Several numerical methods are available, for example the Sobek 1D2D model developed by WL Delft Hydraulics (Asselman and Heynert 2003). In the simulation of flood flows it is important to account for the roughness and geometry of the flooded area. Certain line elements, such as local dikes, roads, railways and natural heights, might create barriers that can significantly influence the flood flow and the area, thereby dividing the area in smaller compartments.

\subsection{Analysis of the exposed population and evacuation}

The number of people exposed to the floodwaters can be estimated based on the following elements:

- The number of people at risk before the event: $N_{\text {PAR }}$;

- The fraction of the population that is evacuated out of the area before the flood: $F_{\mathrm{E}}$;

- The fraction of the (remaining) population that has the possibility to find shelter: $F_{\mathrm{S}}$;

- The number of people rescued: $N_{\text {RES }}$.

The number of people exposed equals:

$$
N_{\mathrm{EXP}}=\left(1-F_{\mathrm{E}}\right)\left(1-F_{\mathrm{S}}\right) N_{\mathrm{PAR}}-N_{\mathrm{RES}}
$$

The analysis of the four elements in this formula is described more in detail below.

\subsubsection{The number of people at risk}

The number of people at risk $\left(N_{\mathrm{PAR}}\right)$ concerns all the individuals in the affected area before the event. For larger affected areas, it can often be approximated by the registered population. However, in some cases it might be necessary to take into account population dynamics, for example when a part of the reference population will be working elsewhere most of the time.

\subsubsection{Evacuation}

Evacuation is defined in this study as "the movement of people from a (potentially) exposed area to a safe location outside that area before they come into contact with physical effects". In general the possibilities for successful evacuation will depend on the time available until the arrival of the floodwater in an area and the time required for evacuation. The fraction of the population $\left(F_{\mathrm{E}}\right)$ that can be evacuated can be estimated based on these two variables. 
The time available for evacuation is determined by two elements: (1) The time available between the first signs and the initiation of the flood, i.e. the breach, and (2) The time available between the breach initiation and the arrival of the floodwaters at a certain location (the so-called arrival time). The time lag between first signs and the initiation of a flood depends on the (threatening) type of flood and the availability of warning systems. For example heavy rainfalls can cause flash floods within several hours, but high river discharges might be predicted days in advance. For the situation in the Netherlands, Barendregt et al. (2005) proposed representative values for the time available for different combinations of the above factors. For example for a coastal flooding from the North Sea they estimate the average time available at $12 \mathrm{~h}$, and the 5\% and $95 \%$ confidence intervals at 4 and $51 \mathrm{~h}$.

The time required for evacuation equals the time needed to complete the following four phases: (1) detection and decision making, (2) warning, (3) response, and (4) actual evacuation. A study of historical evacuations (Frieser 2004) shows that the first three phases are expected to cover several hours each for a large-scale evacuation. The time required for the actual evacuation can be estimated by means of a simulation model that includes traffic flows and the behaviour of the population (see e.g. Simonovic and Ahmad 2005). For analysis of flood evacuation in the Netherlands, a macro-scale traffic model has been developed (van Zuilekom et al. 2005). The model accounts for the number of inhabitants in the area, the capacities of the road network and the exits, the departure time distribution of evacuees and the effects of traffic management. This model provides the time required to evacuate a certain fraction of the population as output. An example of the application of this model is presented in Fig. 9. The study area concerns the dikering 'Land van Heusden/de Maaskant'. It has 360,000 inhabitants and it is threatened by flooding of the river Meuse. The delay in evacuation due to prediction, warning and response has to be taken into account. In addition it needs to be accounted for that a certain fraction of the population does not evacuate, e.g. because they are not warned or refuse to evacuate. For this area a conservative estimate of the time available is $16 \mathrm{~h}$. By combination with the results evacuation model, the evacuated fraction is estimated at $F_{\mathrm{E}}=0.5$ if traffic management is used. $F_{\mathrm{E}}$ reduces to 0.4 if no traffic management is used, e.g. in the case of an unorganized evacuation.

\subsubsection{Shelter}

Within the flooded area people may find protection within shelters. These are constructed facilities in the exposed area, which offer protection. Examples of shelters are high-rise

Fig. 9 Estimation of the time required for evacuation for the area "Land van Heusden/de Maaskant"

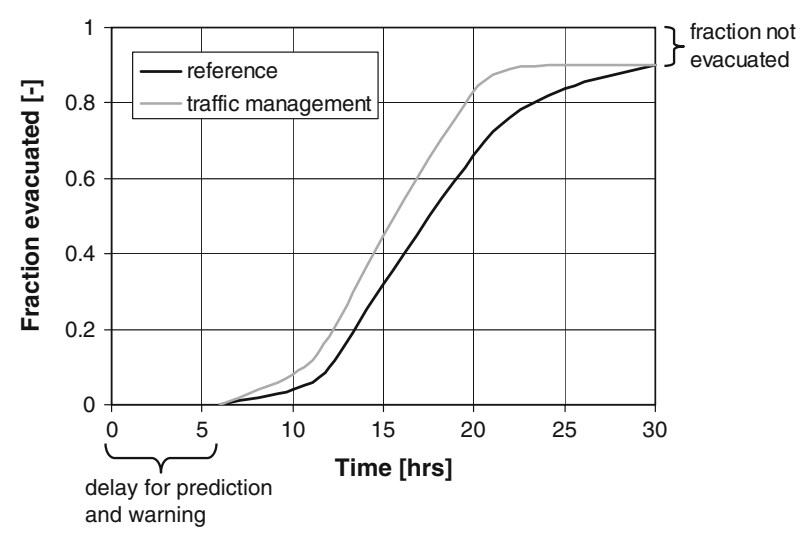


buildings during floods. Evidence from literature (Bern et al. 1993; Chowdhury et al. 1993; McClelland and Bowles 2002) suggests that fatalities in intended shelters have been extremely rare. As a first order approximation of the effects of sheltering, it is proposed to assume that all people present in buildings with more than three stories are safe. In the Netherlands the fraction of people living in higher buildings could range between 0 in rural areas to 0.2 in cities. The possibilities to reach shelter depend on the level of warning, and also on the rise rate and depth of the water. For specific cases the presence of formal shelters and/or high grounds can be discounted additionally.

\subsubsection{Rescue}

Rescue concerns the removal of people from an exposed area either by professionals or other affected people. Rescue only prevents loss of life if people are rescued before they will lose their life due to exposure. The expected survival time for people in cold water is only a few hours, e.g. between 1 and $3 \mathrm{~h}$ for a water temperature of $5^{\circ} \mathrm{C}$ (Hayward 1986). The floods with the greatest life loss have generally claimed their victims before professional rescuers were able to arrive (McClelland and Bowles 2002). Rescue actions are expected to have a limited effect on fatalities in the direct impact phase, i.e. the first hours of the event. A general estimate of the number of people rescued $\left(N_{\mathrm{RES}}\right)$ can be obtained based on estimates of the capacities of rescue services with boats and helicopters. In addition, the delays in the initiation of rescue need to be accounted for.

\subsection{Estimation of the mortality amongst the exposed population}

In this section mortality functions are proposed. First, the general approach and data sources are described. Consequently, the mortality functions for different zones in the flooded area are proposed. These functions and their area of application are also summarized in the Appendix.

\subsubsection{General approach}

After analysis of flood characteristics and evacuation, the next step is the determination of mortality amongst those exposed to the flood. An approach is proposed in which hazard zones are distinguished. Hazard zones are areas that differ with respect to the dominating flood characteristics and the resulting mortality patterns. ${ }^{5}$ Based on the findings from historical events (Sect. 3.1) and past work (Waarts 1992), it was found that many fatalities occur behind breaches and in areas with rapidly rising waters. Three typical hazard zones are distinguished for a breach of a flood defence protecting a low-lying area (see Fig. 10).

- Breach zone: Due to the inflow through the breach in a flood defence high flow velocities generally occur behind the breach. This leads to collapse of buildings and instability of people standing in the flow.

- Zones with rapidly rising waters: Due to the rapid rising of the water, people are not able to reach shelter on higher grounds or higher floors of buildings. This is particularly hazardous in combination with larger water depths.

\footnotetext{
5 The concept of hazard zones is also used in other loss of life models for both coastal and river floods (Ramsbottom et al. 2003) and dam break floods (McClelland and Bowles 2002).
} 


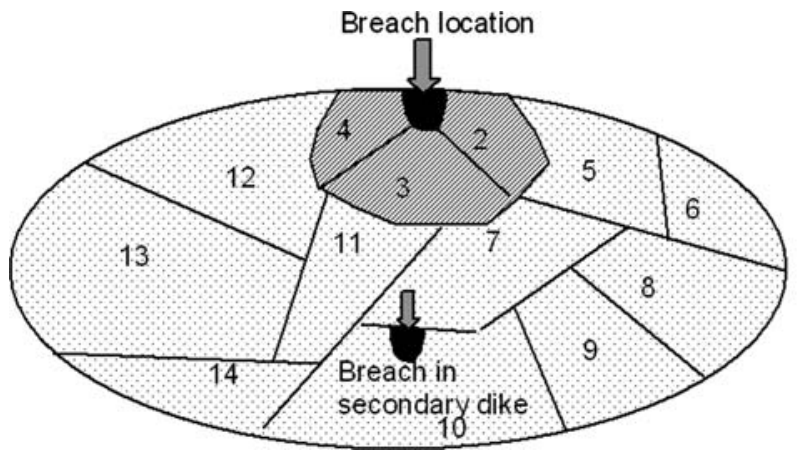

zones:

Breach zone

Zone with rapidly rising water

Remaining zone

Fig. 10 Proposed hazard zones for loss of life estimation. Numbers indicate locations

- Remaining zone: In this zone the flood conditions are more slow-onset, offering better possibilities to find shelter. Fatalities may occur amongst those that did not find shelter, or due to adverse health conditions associated with extended exposure of those in shelters.

For other types of floods, the situation and proportional area of the hazard zones might be different. For example for dam breaks in narrow canyons, the hazard zone associated with high flow velocities will be much larger.

The boundaries of the rapidly rising waters can be formed by line elements that create barriers, such as building rows, lowered streets, dikes or steep contours. Also, depending on the topography of the area and flow patterns, rapid rise of the water or high flow velocities are possible in local compartments or contractions, for example due to breaching of local dikes.

Depending on the variability of flood characteristics it might be necessary to distinguish different locations in the exposed area to give a realistic estimate of loss of life. Each hazard zone can thereby be subdivided into locations; see Fig. 10 for an example. A location is defined in this context as an area for which flood characteristics (water depth, rate of rising, flow velocities) and area characteristics (e.g. shelter possibilities) can be assumed relatively homogeneous. For (relatively) flat areas, locations could include whole polders or villages. If there are large local variations within one village, e.g. in land level, it could be divided into multiple locations. For locations in every hazard zone mortality is estimated by means of a mortality function, which relates the mortality to the local flood characteristics.

\subsubsection{Derivation of mortality functions based on historical flood events}

For the three hazard zones mortality functions have been derived. These functions relate the mortality fraction to flood characteristics. Empirical data from historical flood events are used to analyse whether a statistical relationship exists between the mortality fraction and certain flood characteristics. The mortality functions are derived by means of a least square fit.

In order to derive empirical mortality functions, a dataset with information regarding flood fatalities in historical flood events has been compiled based on available literature. In the dataset information has been included on a large number of factors that are relevant for the investigation of loss of life. The data categories that have been reported for each record include event characteristics (name, location, date), flood characteristics (depth, velocity, 
rise rate), information regarding warning, evacuation, shelter and collapse of buildings, and more descriptive information regarding circumstances and vulnerabilities of flood fatalities. Individual records have been created for locations for which conditions could be assumed relatively homogeneous, so one event can involve multiple locations. To allow empirical analysis, mainly information from references that provide quantitative data is included. Table 5 summarizes the available information per event.

In total the database covers over 165 locations, which have been abstracted from 11 events. The locations included could be considered as separate observations each representing different exposure conditions. The available dataset is split into data used for calibration (i.e. derivation) of the mortality functions and data used for validation (i.e. verification) of the proposed functions. The first five events in Table 5 have been used for calibration (derivation of mortality functions), as these included large numbers of records. The other events, which included single locations, would add limited weight in the statistical analysis and have been used for validation of the model.

The occurrence of flood fatalities is determined by a large number of interacting factors such as individual vulnerabilities, human behaviour and local flood conditions. In order to achieve a robust statistical analysis, only factors for which sufficient data (more than 5 to 10 observations) are available are taken into account. Predominantly for water depth a substantial number of observations is available. Mortality functions will thereby primarily be derived based on water depth, which was also found to be an important determinant of mortality in historical flood events (see Sect. 3.1). The influence of other factors of which data are available, e.g. rise rate, collapse of buildings and warning level, has been investigated. Due to lack of data, other potentially relevant factors, such as debris, flood duration or temperature, could not be included in the empirical analysis

In the compilation of the dataset, a number of issues had to be taken into account, including regional and temporal differences between the events in the dataset (see Jonkman 2007 for a discussion in more detail). With respect to regional differences between events, it is expected that the considered events were all large-scale floods of low-lying areas with similar area and flooding conditions. Temporal differences could emerge because many of the events occurred in the 1950s. Developments since then may have reduced the validity of these datasets for loss of life estimation for contemporary floods. Firstly, main changes concern the possibilities of evacuation, as prediction, warning, communication and transportation systems have improved. Also, the quality of buildings has been improved and nowadays a larger number of higher buildings is available for shelter. McClelland and Bowles (2002) conclude that, if these two factors [(1) warning, evacuation and (2) building quality] are taken into account, life loss patterns appear consistent and similar across time. The influence of these factors is analysed separately in Sects. 3.5.6 and 3.5.7.

\subsubsection{Mortality in the breach zone}

Reports from historical floods show that, if breaching occurs in populated areas, mortality can be high in the area behind the breach. Especially due to the high flow velocities and forces associated with breach inflow, buildings can collapse and people can lose their stability. Some authors have investigated loss of life near breaches (see e.g. Tsuchiya and Yasuda 1980; Waarts 1992; Ramsbottom et al. 2005). None of the available sources in the dataset relates mortality in the breach zone directly to the local flood characteristics (depth and velocity). Thus the available case study data do not provide enough evidence for empirical derivation of mortality functions for the breach zone. Therefore, an approach is 


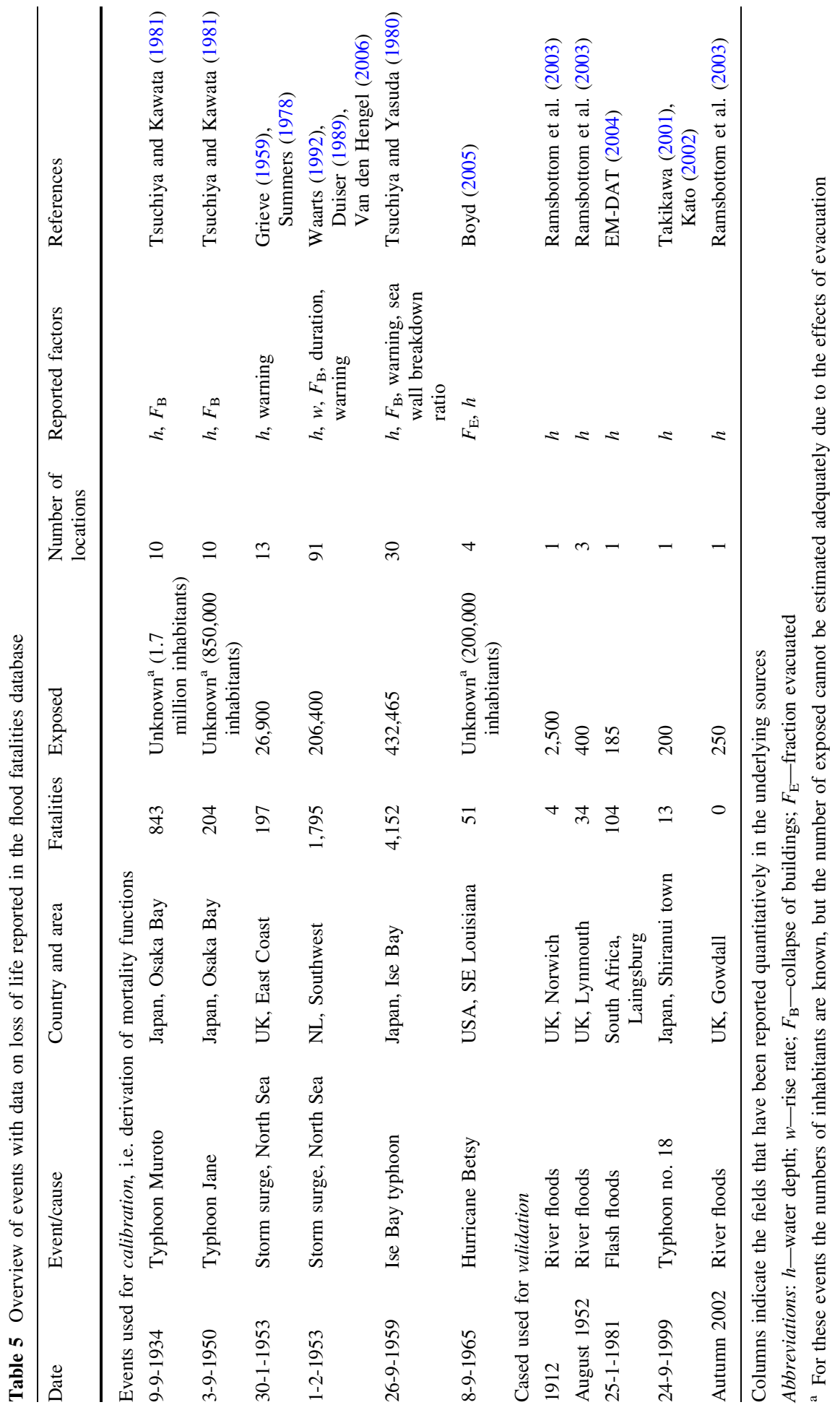


proposed based on information from literature. People's instability and damages to buildings are both generally estimated as a function of the depth-velocity product. Clausen (1989) proposed a criterion for the damage to buildings in flow conditions. Total destruction of masonry, concrete and brick houses occurs if the product of water depth and flow velocity exceeds the following criteria simultaneously:

$$
h v \geq 7 \mathrm{~m}^{2} / \mathrm{s} \text { and } v \geq 2 \mathrm{~m} / \mathrm{s}
$$

It is proposed to use this function to define the boundaries of the breach zone. For the characteristic flood pattern following a breach in a flood defence (see Fig. 10), velocities are high mainly near the breach and more moderate in other parts of the polder. Based on the output of flood simulations, the zone can be defined where the above conditions occur. It is assumed that most people remain indoors during the flood and that people do not survive when the building collapses. Then, it can be assumed that mortality in the breach zone equals $F_{\mathrm{D}}=1$. This assumption may be conservative as those who will be picked up by the flood may still have survival chances, see also Bern et al. (1993) for discussion. ${ }^{6}$

\subsubsection{Mortality in the zone with rapidly rising water}

Rapidly rising water is hazardous as people may be surprised and trapped at lower floors of buildings and have little time to reach higher floors or shelters. The combination of rapid rise of waters with larger water depths is particularly hazardous, as people on higher floors or buildings will also be endangered. Data on fatalities caused by rapidly rising waters are available for the floods in the Netherlands in 1953 (12 locations), in the UK in 1953 (one location) and in Japan in 1959 (two locations). All the points categorized as being in the rapidly rising zone had rise rates of $0.5 \mathrm{~m} / \mathrm{h}$ and the derived function is applicable for situations with a rise rate above this threshold value. For these observations there appears to a rather strong relationship between water depth and mortality (see Fig. 11). This implies that the combination of water depth and rise rate is important. A best fit trendline is found for the lognormal distribution:

$$
\begin{aligned}
& F_{\mathrm{D}}(h)=\Phi_{\mathrm{N}}\left(\frac{\ln (h)-\mu_{\mathrm{N}}}{\sigma_{\mathrm{N}}}\right) \\
& \mu_{\mathrm{N}}=1.46 \quad \sigma_{\mathrm{N}}=0.28
\end{aligned}
$$

where $\Phi_{\mathrm{N}}$ is the cumulative normal distribution; $\mu_{\mathrm{N}}$ is the average of the normal distribution; and $\sigma_{\mathrm{N}}$ is the standard deviation of the normal distribution.

This relationship gives a good correlation between observations and results of the model $\left(R^{2}=0.76\right)$. Additionally, another good fit $\left(R^{2}=0.74\right)$ is obtained with a rising exponential distribution that is also shown in the figure. The exponential function has the disadvantages that it approximates $F_{\mathrm{D}}=1$ very rapidly for higher water depths. The benefit of the lognormal function is that it is also used to model human response of exposure to other substances with so-called probit functions and that it asymptotically approaches $F_{\mathrm{D}}=1$ for higher water depths. No empirical data is available to verify the correctness of the derived function for higher mortality fractions. Some support for the course of the function for higher water depths is provided by an analysis of loss of life in historical dam

\footnotetext{
${ }^{6}$ Bern et al. (1993) investigated risk factors for flood mortality during the 1991 Bangladesh cyclone by conducting a survey amongst people who were affected by the flood. Of the 285 people who were swept away during the storm surge, 112 (39\%) died, implying that $61 \%$ of those people survived.
} 


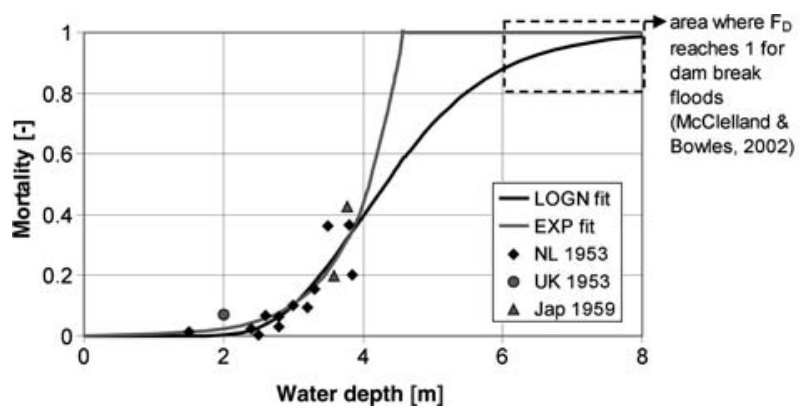

Fig. 11 Relationship between mortality and water depth for locations with rapidly rising water

break floods (McClelland and Bowles 2002). They found that when the water depth reaches about $6.5 \mathrm{~m}$ (20 feet) mortality becomes $100 \%$. To strengthen the empirical basis of this curve further collection of data is recommended, especially for larger water depths.

\subsubsection{Remaining zone}

A remaining zone is distinguished to account for fatalities outside the breach and rapidly rising zones. In this zone the flood conditions are more slow-onset $(w<0.5 \mathrm{~m} / \mathrm{h})$, offering better possibilities to find shelter. Fatalities may occur amongst those that did not find shelter, or due to adverse health conditions associated with extended exposure of those in shelters. The first five case histories in Table 5 (Japan 1934, 1950, 1959, Netherlands and United Kingdom 1953, US 1965) provide data on mortality in the remaining zone for 93 locations. Mortality fractions are plotted as a function of water depth in Fig. 12.

The following mortality function is found for the lognormal distribution:

$$
\begin{aligned}
& F_{\mathrm{D}}(h)=\Phi_{\mathrm{N}}\left(\frac{\ln (h)-\mu_{\mathrm{N}}}{\sigma_{\mathrm{N}}}\right) \\
& \mu_{\mathrm{N}}=7.60 \quad \sigma_{\mathrm{N}}=2.75
\end{aligned}
$$

A very weak correlation between observations and model calculation of $R^{2}=0.09$ is obtained. The poor correlation is influenced by some outliers with high mortality. For example during the floods at the east coast of the UK in 1953, 2 of the 37 inhabitants of Wallasea Island did not survive resulting in a 0.054 mortality. The level of warning is expected to influence the possibilities to find local shelter and thus influences loss of life, see the discussion in the next section. The derived mortality function gives a poor fit for absolute mortality, but it provides insight in the order of magnitude of mortality, which is generally between 0 and 0.02 .

A summary of the derived mortality functions for the three zones and their area of application is proved in Appendix.

\subsubsection{Effects of warning on mortality}

Even when people cannot evacuate from the exposed area, timely warning may still play an important role in preventing loss of life. It will allow people some time to find shelter on higher grounds or in buildings. Information regarding warning levels is available for two of the historical events. Tsuchiya and Yasuda (1980) investigated the relationship between risk to life and warning for the Ise Bay typhoon in 1959 in Japan for 27 locations. The 
Fig. 12 Mortality as function of water depth for the remaining zone

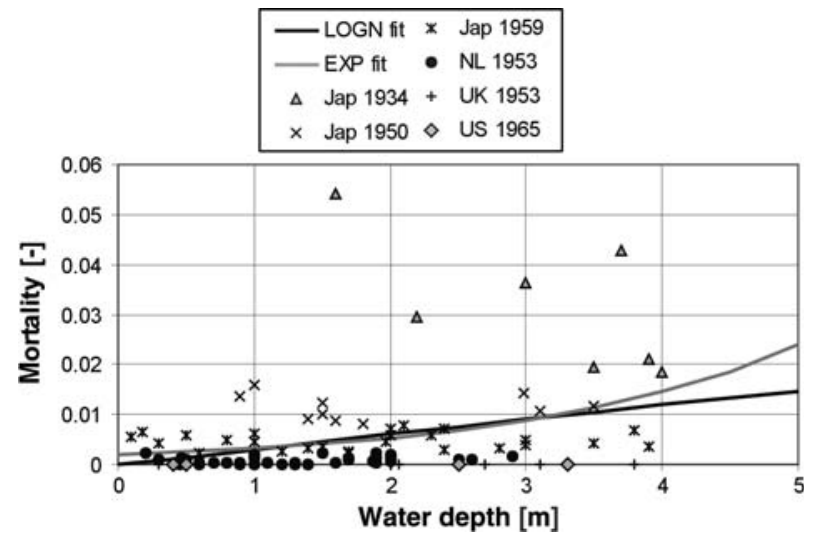

authors categorized the local level of warning by using the ranking system indicated in Table 6. The same classification was applied to locations affected by the 1953 floods in the Netherlands. A large-scale and organized evacuation was not possible, but this disaster did not occur completely unexpected at all locations. In many of the flooded locations, some sort of warning (e.g. by church bells) was given and people had the possibility to move to higher grounds or buildings. Based on qualitative descriptions in memorial volumes and eyewitness accounts (Slager 1992), the warning levels for 39 locations have been rated with the classification system from Table 6.

Figure 13 shows the relationship between water depth, flood mortality and level of warning for locations in the remaining zone from the two case studies (Netherlands 1953 and Japan 1959). It shows that observed mortalities in the remaining zone were highest where (a) little (C) or no warning (D) was given and (b) where water depths were high. Further analysis shows that many outliers in the remaining zone (see also Fig. 12) had a poor level of warning or no warning at all. For other outliers (e.g. Wallasea Island) no information is available on the level of warning. The above results suggest that the level warning has an influencing on mortality in the remaining zone. However, differentiation of mortality functions by the level of warning does not lead to an improvement of correlation between observations and prediction. Further research in this direction is recommended.

\subsubsection{Effects of the collapse of buildings on mortality}

Historical flood events show that death rates are high where buildings collapse and fail to provide a safe shelter. Especially wooden buildings, mobile homes, informal, temporary

Table 6 Classification of flood warning levels according to Tsuchiya and Yasuda (1980)

\begin{tabular}{ll}
\hline Warning rank & Description \\
\hline A & $\begin{array}{l}\text { Evacuation order was proclaimed beforehand and people could take refuge before flood } \\
\text { B }\end{array}$ \\
C & $\begin{array}{c}\text { completely finished } \\
\text { Warning was given shortly before or just after the flood and some people managed to } \\
\text { take action }\end{array}$ \\
D & No warning given, warning perceived by hardly anyone \\
\hline
\end{tabular}




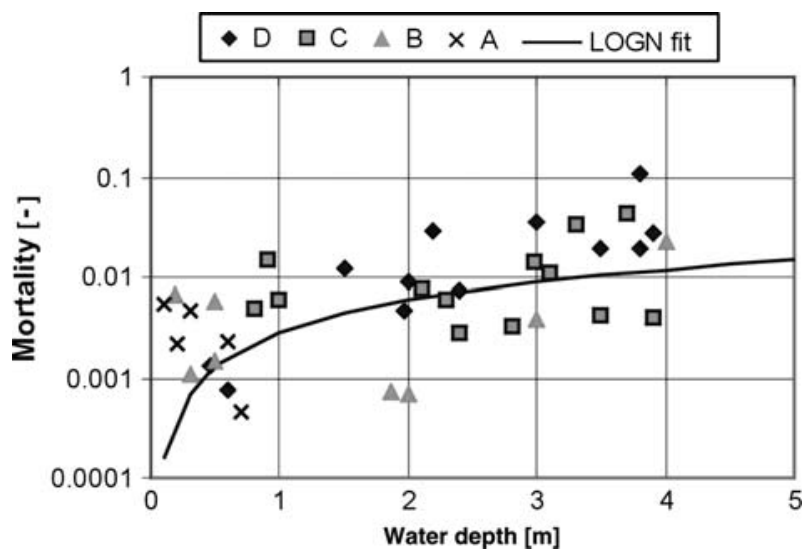

Fig. 13 Relationship between mortality (logarithmic scale) and water depth for different levels of warning. The line shows the mortality function for the remaining zone derived in Sect. 3.5.5

and fragile structures (including campsites and other tented dwellings) may give rise to significant loss of life (Ramsbottom et al. 2003). Particularly during more severe and unexpected coastal floods, such as those in the UK and Netherlands in 1953, building vulnerability has been an important factor influencing the large numbers of deaths.

Several authors have developed methods for the analysis of the collapse of buildings in floods (see e.g. Roos 2003; Kelman and Spence 2004). Some work has considered the relationship between collapse of buildings and loss of life in floods. Graham (1999) shows that for dam breaks the highest fatality rates occurred in the zones where residences were destroyed.

The relationship between the collapse of buildings and mortality is further investigated for the floods in the Netherlands in 1953 using available data for different locations. Figure 14 plots the relationship between the fraction of the total number of buildings that collapsed $\left(F_{\mathrm{B}}\right)$ and mortality $\left(F_{\mathrm{D}}\right)$, for locations in the zone with rapidly rising water and the remaining zones.

For the zone with rapidly rising water, a rather strong correlation $\left(R^{2}=0.73\right)$ exists between collapse of buildings and mortality. The function can be approximated with $F_{\mathrm{D}}=0.37 F_{\mathrm{B}}$. A rapid rise of the water leads to pressure differentials between water levels inside and outside the building (Kelman 2002). This effect, in combination with the effects of water depth and flow velocity, could contribute to the collapse of buildings. In the above linear function mortality becomes 0 if collapse of buildings reduces to $F_{\mathrm{B}}=0$. However, it is still likely that fatalities will occur due to other causes. Therefore an asymptotic relationship is assumed and schematically shown in Fig. 14. Figure 14 shows that for the remaining zone a less strong relationship exists between collapse of buildings and mortality. In this zone the flood are more slow-onset, and people have more time to find shelter at safer locations. Based on these findings, it is assumed that collapse of buildings is only a significant factor in the zone with rapidly rising waters.

During the 1953 floods many of the collapsed buildings were working class houses of poor quality. Current building quality is better, and this could be accounted for in the mortality function. Based on Asselman (2005), it is estimated that improvement of building quality to today's standards would lead to a reduction in collapse of buildings of approximately $60 \%$ relative to the 1953 event. The above analysis indicated a linear 
Fig. 14 Relationship between the fraction of buildings collapsed and mortality by location for the 1953 floods in the Netherlands

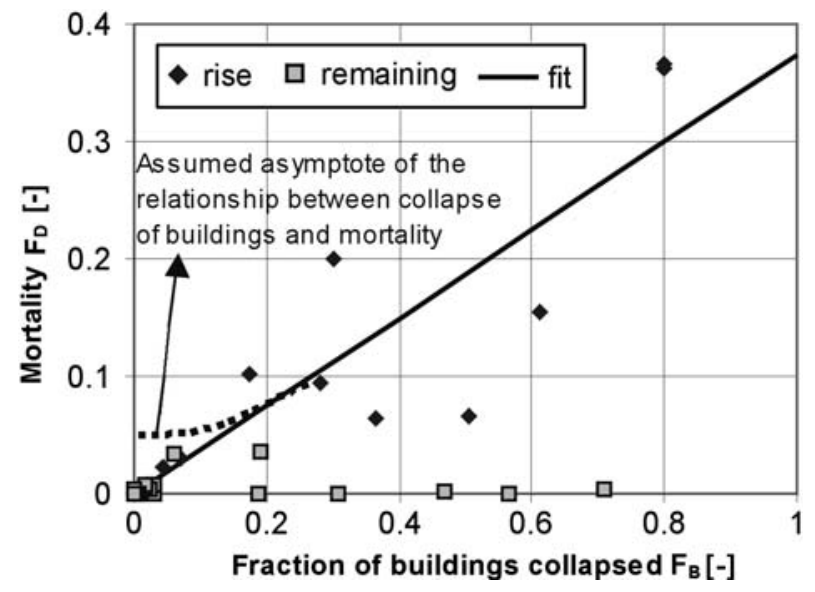

relationship between collapse ratio and mortality for the zone with rapidly rising water. Then, observed mortality fractions for the 1953 storm surge in the Netherlands can be scaled with the same factor to account for improved building quality. Thereby a new mortality function for the rapidly rising zone can be derived with parameters $\mu_{\mathrm{N}}=1.68, \sigma_{\mathrm{N}}$ $=0.37$ in Eq. 16. It is noted that this (corrected) function is mainly based on the situation in the Netherlands. For other regions, where other building types are used, different relationships could be developed.

\subsection{Validation of the method}

As a first order validation, the outcomes of the proposed method for loss of life estimation are compared with observations from some historical flood events. Five flood events included in the flood fatalities database are investigated. The selected events concern a flash flood (event in Laingsburg South Africa 1984), a coastal flood (Shiranui Town, Japan, 1999) and three river floods in the UK that have been analysed in Ramsbottom et al. (2003) and Penning-Rowsell et al. (2005). Table 7 compares the results following from the proposed method with observed mortality and fatality numbers. Overall, the results show good agreement between observations and model results. For all events the mortality (and the number of fatalities) are estimated within a bandwidth of a factor 2, except for the Lynmouth case.

Van den Hengel (2006) applied the proposed mortality functions to give a hindcast of the consequences of the 1953 storm surge flood in the Netherlands. As input for flood characteristics he used available flood simulations of the disaster. The exposed population was estimated based on historical maps and population data. He found that it was possible to give a reasonable approximation of the total number of fatalities for the whole disaster (1,298 observed fatalities in the considered areas versus 1,705 predicted). However, locally (e.g. per village) larger deviations existed between the observed and the predicted number of fatalities. These deviations are due to various factors including: differences between the observed and the simulated water depth and the sensitivity of outcomes for a location for the value of the rise rate. 
Table 7 Comparison between reported mortality figures for some historical flood events and the results calculated with the proposed method

\begin{tabular}{|c|c|c|c|c|c|c|}
\hline \multirow[t]{2}{*}{ Flood } & \multirow[t]{2}{*}{ Flood type } & \multicolumn{3}{|c|}{ Observations } & \multicolumn{2}{|l|}{ Method } \\
\hline & & Exposed & Fatalities & Mortality & Fatalities & Mortality \\
\hline Norwich river floods, 1912 & River & $1,250^{\mathrm{a}}$ & 4 & $1.6 \cdot 10^{-3}$ & 5 & $3.6 \cdot 10^{-3}$ \\
\hline Lynmouth floods, 1952 & River/flash & 400 & 34 & 0.085 & 11 & 0.028 \\
\hline $\begin{array}{l}\text { Laingsburg, South Africa, } \\
1981\end{array}$ & Flash & 185 & 104 & 0.56 & 73 & 0.39 \\
\hline Shiranui Town, Japan, 1999 & Coastal & 200 & 13 & 0.065 & 7 & 0.035 \\
\hline Gowdall river floods, 2002 & River & $25^{\mathrm{a}}$ & 0 & 0 & 0.07 & $2.8 \cdot 10^{-3}$ \\
\hline
\end{tabular}

a Based on descriptions by Ramsbottom et al. (2003), evacuation has been assumed for the Norwich and Gowdall events

\section{Case study: flooding of South Holland}

The proposed method for loss of life estimation has been used to predict the loss of life associated with a flood in the area of South Holland in the Netherlands. This area has approximately 3.6 million inhabitants and it includes major cities, such as The Hague, Rotterdam and Amsterdam. Parts of this area can be flooded due to coastal flooding from the North Sea and river flooding from the South. Thereby, different flood scenarios are possible and the consequences for these scenarios have been analysed in the context of a risk assessment study (Rijkswaterstaat 2006; Jonkman and Cappendijk 2006). Below, the consequences for an extreme but possible coastal flood scenario are presented. It concerns an event that leads to two breaches in the coastal flood defences, at the locations The Hague (see Fig. 15) and Ter Heijde. As much of the hinterland is below sea level, the event will lead to large-scale flooding. Figure 15 shows the flooded area and the flood depths in this area. In the deepest locations the flood depths can exceed $4 \mathrm{~m}$ for the considered scenario. A densely populated area with approximately 700,000 inhabitants is flooded. The possibilities for an evacuation of this area are expected to be very limited. For a coastal flood event there is only $12-24 \mathrm{~h}$ available for evacuation. The time required to evacuate the flooded area of South Holland is estimated with an evacuation model and appears to be much larger, approximately $50 \mathrm{~h}$ (Van der Doef and Cappendijk 2006). Thereby it is estimated that only a very limited fraction of the population $(\sim 15 \%)$ will be able to evacuate before the flood. The proposed mortality functions are applied to estimate the number of fatalities for the area. The total number of estimated fatalities is almost 3,200. Table 8 summarizes the results regarding the exposed population and the fatalities. Figure 15 shows the spatial distribution of fatalities in the area. The majority of fatalities, nearly 1,900 , occur in areas with deep flood depths and rapidly rising waters.

The number of fatalities in the zones with rapidly rising waters is sensitive to the values of the rise rates used as input (if the rise rate exceeds $0.5 \mathrm{~m} / \mathrm{h}$ the function for the zone with rapidly rising waters is used-see above). The consequences for a single scenario are strongly influenced by the choice of outside hydraulic load conditions (storm surge height and duration), and the modelling of breach growth and the course of flooding. Also, the assumed number of breaches and their locations are important. Line elements, such as roads, railways and old dikes, could affect the flood flow. Population response and behaviour might affect evacuation success and loss of life. The number of fatalities is proportional to the number of people exposed. The number of evacuated thus has an important influence on the number of fatalities. 


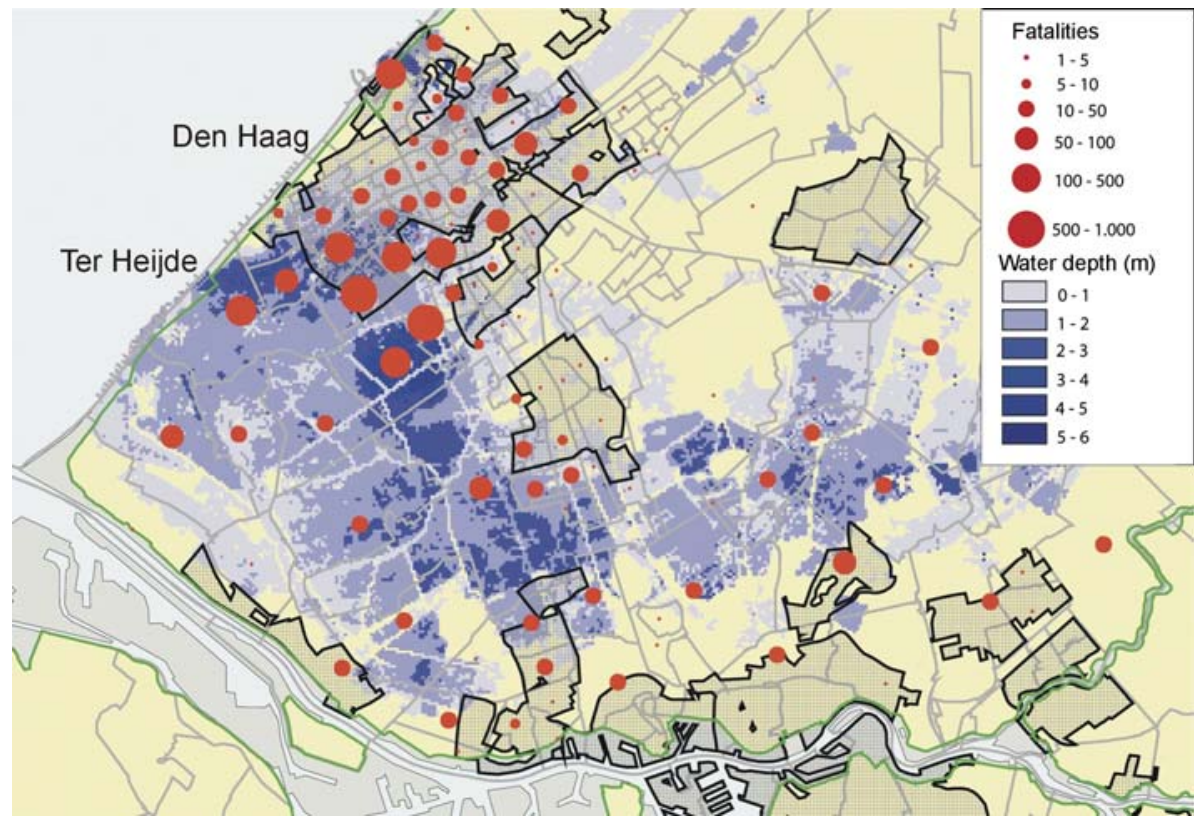

Fig. 15 Fatalities by neighbourhood and water depths for the flood scenario with breaches at Den Haag and Ter Heijde

Table 8 Summary of the results for the flood scenario with breaches at Den Haag and Ter Heijde

Number of inhabitants in flooded area

706,650

Number of evacuated people (in case of organized evacuation)

Number of exposed people

647,420

Estimated number of fatalities

3,170

Fatalities in the breach zone

Fatalities in the zone with rapidly rising water

Fatalities in the remaining zone

a The area covered by the breach zone is relatively small and does not cover populated areas

\section{Concluding remarks}

In the first part of this article, existing methods for the estimation of loss of life that are used in different regions and for different types of floods (e.g. for dam breaks, coastal floods, tsunamis) have been reviewed. This showed that the existing models do not take into account all of the most relevant determinants of loss of life and that they are often to a limited extent based on empirical data of historical flood events. Therefore, a new method has been proposed for the estimation of loss of life due to the flooding of low-lying areas due to breaching of flood defences. The method is primarily developed for the Netherlands but it is expected to be applicable to similar low-lying areas in other parts of the world. The method takes into account the characteristics of the flood, the extent of the exposed population and mortality amongst those exposed. Based on empirical data from historical flood events, mortality functions have been developed. The method takes into account the 
most relevant characteristics that determine loss of life and it has a strong empirical foundation. Comparison of the outcomes of the proposed method with information from historical flood events shows that it gives an accurate approximation of the number of fatalities. For most of the considered validation cases, the predicted loss of life deviates less than a factor two from the observed mortality. The method can thereby be used to give an indicative estimate of the loss of life for a flood event.

The outcomes of the method are sensitive to the chosen flood scenario (especially the number of breaches and the size of the flooded area) and the rise rate of the floodwater. Analysis of available data suggests that the level of warning of the population and the collapse of buildings could have an effect on the mortality. Further investigation of these and other factors based on empirical data is recommended. One important factor that needs further investigation is the effect of the rise rate on the loss of life. Therefore it is needed to further collect and analyse data of flood events. Standardized collection and reporting of the available data for flood disasters are recommended as a basis for further analysis (WHO 2002; Hajat et al. 2003; Jonkman and Kelman 2005). It is strongly recommended to analyse the available data for the flooding of New Orleans in the year 2005 within the framework presented in this article. Some preliminary findings related to the loss of life due to flooding of New Orleans are discussed in Jonkman (2007).

Application of the method to a hypothetical but possible flood scenario for the area of South Holland in the Netherlands shows that a large-scale flood in this area could lead to more than 3,000 fatalities. Similar estimates of the consequences have been made for other flood scenarios in this area (Jonkman and Cappendijk 2006). Results indicate that flooding of South Holland can result in hundreds or (for some scenarios) even thousands of fatalities. Based on these results further investigation of possibilities for improvement of evacuation of the population of South Holland, and development of alternative strategies, e.g. for shelter in place, is strongly recommended. Information regarding the elaborated flood scenarios and consequence estimates can be used for the development and improvement of such emergency management strategies.

By combination of the loss of life estimates with available information regarding the probability of occurrence of flood scenarios, the flood risks can be estimated. These results can be used as input for the decision-making regarding flood protection levels and strategies. Eventually, it has to be decided in a societal and political debate whether the level of flood risk is acceptable and if risk reduction is necessary.

Acknowledgements This work was supported by Rijkswaterstaat, the Dutch Directorate General of Public Works and Water Management.

Open Access This article is distributed under the terms of the Creative Commons Attribution Noncommercial License which permits any noncommercial use, distribution, and reproduction in any medium, provided the original author(s) and source are credited.

\section{Appendix: Summary of the approach for loss of life estimation}

This appendix briefly summarizes the areas of application of the derived mortality functions. Mortality for the different hazard zones can be estimated as follows:

Mortality in the breach zone:

$$
F_{\mathrm{D}}=1 \quad \text { if } h v \geq 7 \mathrm{~m}^{2} / \mathrm{s} \text { and } \quad v \geq 2 \mathrm{~m} / \mathrm{s}
$$


Mortality in the zone with rapidly rising water:

$$
\begin{aligned}
& F_{\mathrm{D}}(h)=\Phi_{\mathrm{N}}\left(\frac{\ln (h)-\mu_{\mathrm{N}}}{\sigma_{\mathrm{N}}}\right) \\
& \mu_{N}=1.46 \quad \sigma_{N}=0.28 \\
& \text { if }(h \geq 2.1 \mathrm{~m} \text { and } \quad w \geq 0.5 \mathrm{~m} / \mathrm{h}) \text { and }\left(h v<7 \mathrm{~m}^{2} / \mathrm{s} \text { or } v<2 \mathrm{~m} / \mathrm{s}\right)
\end{aligned}
$$

The function for the zone with rapidly rising water is only used when it gives higher mortality fractions than the function for the remaining zone, so for water depths larger than $2.1 \mathrm{~m}$.

The mortality function for the zone with rapidly rising water can be corrected for improved building quality to current standards. For a first-order estimate of this effect, the following constants can be assumed in the lognormal mortality function: $\mu_{\mathrm{N}}=1.68, \sigma_{\mathrm{N}}=0.37$.

Mortality in the remaining zone:

$$
\begin{aligned}
& F_{\mathrm{D}}(h)=\Phi_{\mathrm{N}}\left(\frac{\ln (h)-\mu_{\mathrm{N}}}{\sigma_{\mathrm{N}}}\right) \\
& \mu_{\mathrm{N}}=7.60 \quad \sigma_{\mathrm{N}}=2.75 \\
& \text { if }(w<0.5 \mathrm{~m} / \mathrm{h} \text { or }(w \geq 0.5 \mathrm{~m} / \mathrm{h} \text { and } h<2.1 \mathrm{~m})) \text { and }\left(h v<7 \mathrm{~m}^{2} / \mathrm{s} \text { or } \quad v<2 \mathrm{~m} / \mathrm{s}\right)
\end{aligned}
$$

The range of flood conditions for which the above mortality functions can be applied are indicated in Fig. 16. For clarity, a distinction is made between situations with rise rates below and above the threshold value of $w=0.5 \mathrm{~m} / \mathrm{h}$. The proposed mortality functions
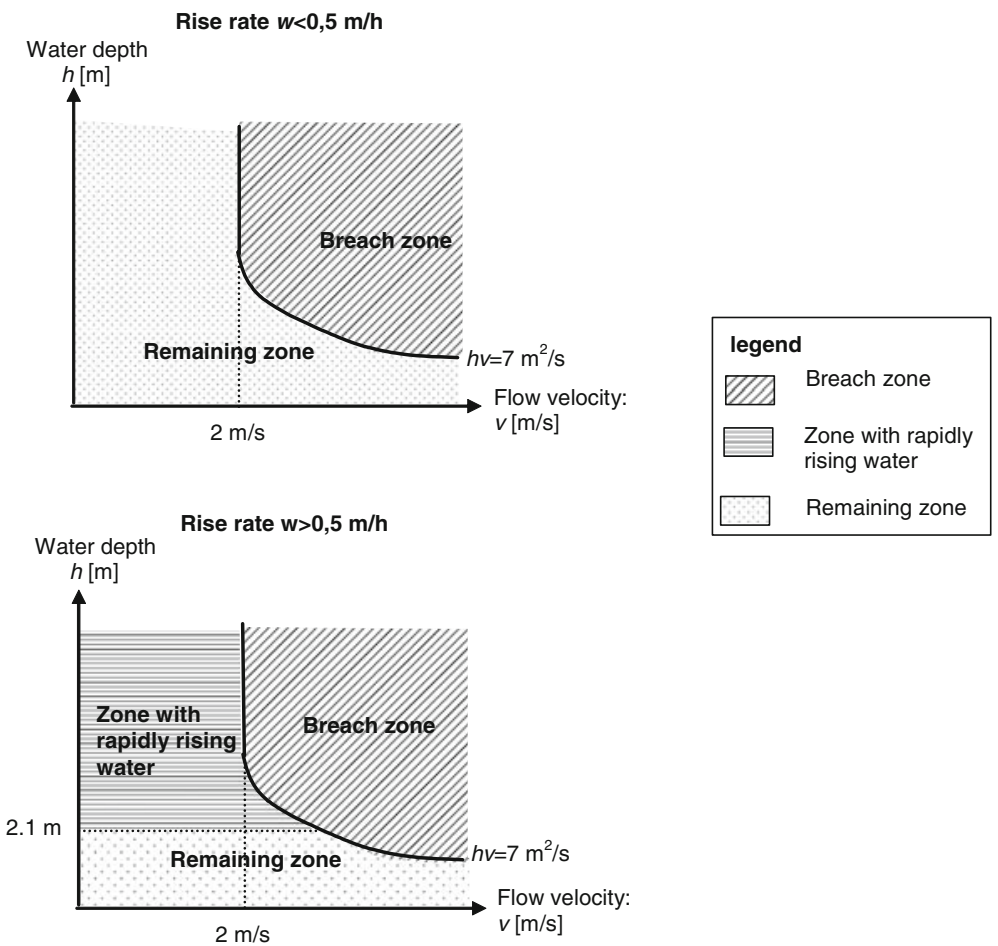

Fig. 16 Area of application of mortality functions, as a function water depth, rise rate and flow velocity 
can be easily implemented into computer code, for example the standardized damage model used in the Netherlands (Kok et al. 2005).

\section{References}

Aboelata M, Bowles DS, McClelland DM (2002) GIS model for estimating dam failure life loss. In: Proceedings of the 10th engineering foundation conference on risk-based decisionmaking. Santa Barbara, pp 126-145

Abt SR, Wittler RJ, Taylor A, Love DJ (1989) Human stability in a high flood hazard zone. Water Resour Bull 25(4):881-890

Ahern M, Kovats SR, Wilkinson P, Few R, Matthies F (2005) Global health impacts of floods: epidemiologic evidence. Epidemiol Revi 27:36-46

Assaf, H, Hartford DND (2002) A virtual reality approach to public protection and emergency preparedness planning in dam safety analysis. In: Proceedings of the Canadian dam association conference, Victoria

Asselman NEM (2005) Consequences of floods—damage to buildings and casualties, WL Delft Hydraulics report Q3668

Asselman NEM, Heynert K (2003) Consequences of floods: 2D hydraulic simulations for the case study area of Central Holland, Delft Cluster report DC 1-233-5

Barendregt A, van Noortwijk JM, van der Doef M, Holterman SR (2005) Determining the time available for evacuation of a dike-ring area by expert judgement. In: Proceedings of the international symposium on stochastic hydraulics (ISSH), 23-24 May, Nijmegen

Bern C, Sniezek J, Mathbor GM, Siddiqi MS, Ronsmans C, Chowdhury AMR, Choudhury AE, Islam K, Bennish M, Noji E, Glass RI (1993) Risk factors for mortality in the Bangladesh cyclone of 1991. Bull WHO 71:73-78

Berz G, Kron W, Loster T, Rauch E, Schimetschek J, Schmieder J, Siebert A, Smolka A, Wirtz A (2001) World map of natural hazards - a global view of the distribution and intensity of significant exposures. Nat Hazards 23(2-3):443-465

Boyd E (2005) Toward an empirical measure of disaster vulnerability: storm surges, New Orleans, and Hurricane Betsy. Poster presented at the 4th UCLA conference on public health and disasters, Los Angeles, 1-4 May 2005

Boyd E, Levitan M, van Heerden I (2005) Further specification of the dose-response relationship for flood fatality estimation. Paper presented at the US-Bangladesh workshop on innovation in windstorm/storm surge mitigation construction. National Science Foundation and Ministry of Disaster \& Relief, Government of Bangladesh. Dhaka, 19-21 December 2005

Brown CA, Graham WJ (1988) Assessing the threat to life from dam failure. Water Resour Bull 24(6): 1303-1309

CDMC (Central Disaster Management Council) (2003) Damage estimation method for the Tonankai and Nankai Earthquakes. http://www.bousai.go.jp/jishin/chubou/nankai/10/sankou_siryou.pdf. Accessed January 2006

Chowdhury A, Mushtaque R, Bhuyia AU, Choudhury AY, Sen R (1993) The Bangladesh cyclone of 1991: why so many people died. Disasters 17(4):291-304

Clausen, LK (1989) Potential dam failure: estimation of consequences, and implications for planning. Unpublished M.Phil. thesis at the School of Geography and Planning at Middlesex Polytechnic collaborating with Binnie and Partners, Redhill

Coates L (1999) Flood fatalities in Australia, 1788-1996. Aust Geogr 30(3):391-408

DeKay ML, McClelland GH (1993) Predicting loss of life in cases of dam failure and flash flood. Risk Anal 13(2): 193-205

Doocy S, Rofi A, Moodie C, Spring E, Bradley S, Burnham G, Robinson C (2007) Tsunami mortality in Aceh Province. Indonesia. Bull WHO 85:273-278

Duiser JA (1989) Een verkennend onderzoek naar methoden ter bepaling van inundatieschade bij doorbraak, TNO report ref. 82-0644

EM-DAT (Emergency events database) (2004) OFDA/CRED International Disaster Database from http://www.cred.be/emdat, Université Catholique de Louvain, Brussels. Accessed December 2004

Frieser B (2004) Probabilistic evacuation decision model for river floods in the Netherlands. MSc thesis, TU Delft

Graham, WJ (1999) A procedure for estimating loss of life caused by dam failure. Dam safety office report DSO-99-6

Green C (2001) Assessing vulnerability to flooding. Draft working paper

Grieve H (1959) The great tide. Waterlow \& Sons Limited 
Guha-Sapir D, Parry LV, Degomme O, Joshi PC, Saulina Arnold JP (2007) Risk factors for mortality and injury: post-tsunami epidemiological findings for Tamil Nadu. Centre for Research on the Epidemiology of Diasters (CRED) report, April 2006, Brussels, Belgium

Hajat S, Ebi KL, Kovats S, Menne B, Edwards S, Haines A (2003) The human health consequences of flooding in Europe and the implications for public health. J Appl Environ Sci Public Health 1(1):13-21

Hartford DND, Baecher GB (2004) Risk and uncertainty in dam safety. Thomas Telford Publishing, London

Hayward, JS (1986) The physiology of immersion hypothermia. In: The nature and treatment of hypothermia, University of Minnesota Press, pp 3-19

IPET (Interagency Performance Evaluation Task Force) (2007) Performance evaluation of the New Orleans and Southeast Louisiana hurricane protection system-volume VII: the consequences, Final report 26 March 2007

Johnstone W, Assaf H, Sakamoto D, Hartford D (2003) Analysis of the Malpasset dam failure using GIS and engineering models. In: Proceedings of GeoTec 2003. Vancouver

Johnstone WM, Sakamoto D, Assaf H, Bourban S (2005) Architecture, modelling framework and validation of BC Hydro's virtual reality life safety model. In: Vrijling et al (eds) Proceedings of the international symposium on stochastic hydraulics, Nijmegen, 23-24 May 2005

Jonkman SN (2001) Overstromingsrisico's: een onderzoek naar de toepasbaarheid van risicomaten. MSc. Thesis, TU Delft

Jonkman SN (2004) Methode voor de bepaling van het aantal slachtoffers ten gevolge van een grootschalige overstroming. DWW report DWW-2004-042

Jonkman SN (2005) Global perspectives of loss of human life caused by floods. Nat Hazards 34:151-175

Jonkman SN (2007) Loss of life estimation in flood risk assessment—-theory and applications. PhD thesis, Delft University

Jonkman SN, Cappendijk P (2006) Veiligheid Nederland in kaart - inschatting van het aantal slachtoffers ten gevolge van overstroming, DWW report DWW-2006-012

Jonkman SN, Kelman I (2005) An analysis of causes and circumstances of flood disaster deaths. Disasters 29(1):75-97

Jonkman SN, van Gelder PHAJM, Vrijling JK (2002) Loss of life models for sea- and river floods. In: Wu et al (eds) Proceedings of flood defence, vol 1. Science Press, New York Ltd., New York, USA, pp 196-206

JWF (Japan Water Forum) (2005) Typhoon Isewan (Vera) and its lessons. Japan Water Forum report

Karvonen RA, Hepojoki A, Huhta HK, Louhio A (2000) The use of physical models in dam-break analysis, RESCDAM Final Report. Helsinki University of Technology, Helsinki

Kato F (2002) A review of flood damage estimation in Japan. Draft working document

Kelman I (2002) Physical vulnerability of residential properties in coastal, eastern England. PhD dissertation, Cambridge University

Kelman I (2003) CURBE fact sheet 3: U.K. Deaths from the 1953 Storm Surge. Version 3, 5 July 2003. http://www.arct.cam.ac.uk/curbe/CURBEFactSheet3UK1953Deaths.doc. Accessed August 2003

Kelman I, Spence R (2004) An overview of flood actions on buildings. Eng Geol 73:297-309

Kok M, Huizinga HJ, Meijerink TC, Vrouwenvelder ACWM, Vrisou van Eck N (2002) Standaardmethode 2002: Schade en slachtoffers als gevolg van overstromingen. HKV and TNO Report PR582.10

Kok M, Huizinga HJ, Vrouwenvelder ACWM, van den Braak WEW (2005) Standaardmethode 2005 schade en slachtoffers als gevolg van overstromingen. HKV report PR999.10

Koshimura S, Katada T, Mofjeld HO, Kawata Y (2006) A method for estimating casualties due to the tsunami inundation flow. Nat Hazards 39:265-274

Lind N, Hartford D (2000) Probability of human instability in a flooding: a hydrodynamic model. In: Melchers E, Stewart MG (eds) Proceedings of ICASP 8, applications of statistics and probability, Balkema, Rotterdam, the Netherlands, pp 1151-1156

Lind N, Hartford D, Assaf H (2004) Hydrodynamic models of human instability in a flood. J Am Water Resour Assoc 40(1):89-96

McClelland DM, Bowles DS (1999) Life-loss estimation: what can we learn from case histories. In: Proceedings of the Australian committee on large dams (ANCOLD) annual meeting. Jindabyne, November 1999

McClelland DM, Bowles DS (2002) Estimating life loss for dam safety risk assessment - a review and new approach. IWR report 02-R-3

Nishikiori N, Abe T, Costa DGM, Dharmaratne SD, Kunii O, Moji K (2006) Who died as a result of the tsunami? Risk factors of mortality among internally displaced persons in Sri Lanka: a retrospective cohort analysis. BMC Public Health No. 6, Art. No. 73, 20 March 2006

Penning-Rowsell E, Floyd P, Ramsbottom D, Surendran S (2005) Estimating injury and loss of life in floods: A deterministic framework. Nat Hazards 36(1-2):43-64 
Pollard M (1978) North Sea surge: the story of the east coast floods of 1953. Terence Dalton Limited, Lavenham and Suffolk

Ramsbottom D, Floyd P, Penning-Rowsell E (2003) Flood risks to people-phase 1. R\&D Technical report FD2317TR

Ramsbottom D, Wade S, Bain V., Hassan M, Penning-Rowsell E, Wilson T, Fernandez A, House M, Floyd P (2004) R\&D outputs: flood risks to people. Phase 2. FD2321/IR2. Department for the Environment, Food and Rural Affairs/Environment Agency

Reiter P (2001) Rescdam: loss of life caused by dam failure, the Rescdam LOL method and its application to Kyrkosjarvi dam in Seinajoki (summary of the final report), 19 June 2001

Rijkswaterstaat (2006) Flood risks and safety in the Netherlands-full report. Rijkswaterstaat report DWW 2006-014. ISBN 90-369-5604-9

Rofi A, Doocy S, Robinson C (2006) Tsunami mortality and displacement in Aceh province, Indonesia. Disasters 30(3):340-350

Roos W (2003) Damage to buildings. Delft Cluster report DC1-233-9

Simonovic SP, Ahmad S (2005) Computer-based model for flood evacuation emergency planning. Nat Hazards 24(1):25-51

Slager K (1992) De ramp - een reconstructie - 200 ooggetuigen over de watersnood van 1953, verhalen om nooit te vergeten. Goes: De koperen tuin

Suetsugi K (1998) Control of floodwater and improvements of evacuation system for floodplain management. In: Fukuoka S (ed) Floodplain risk management, Proceedings of an international workshop. Hiroshima, 11-13 November 1996, pp 191-207

Sugimoto T, Murakami H, Yozuki K, Nishikawa K, Shimada T (2003) A human damage prediction method for tsunami disasters incorporating evacuation activities. Nat Hazards 29(3):585-600

Summers D (1978) The east coast floods. David \& Charles (Publishers) Limited, London

Takikawa K (2001) Storm surge damage caused by Typhoon No. 9918 in the area of Shiranui Sea, JSCE publication. http://www.jsce-int.org/civil_engineering/2001/typhoon.pdf. Accessed December 2005

Tsuchiya Y, Kawata Y (1981) Risk to life, warning systems, and protective construction against past storm surges in Osaka Bay. J Nat Disaster Sci 3(1):33-56

Tsuchiya Y, Yasuda T (1980) High tide and life risk, refuge warning in relation to the Ise Bay Typhoon. J Nat Disaster Sci 2(2):27-60

USBR (U.S. Bureau of Reclamation, U.S. Department of the Interior) (1988) Downstream hazard classification guidelines. Acer technical memorandum no. 11

Van den Hengel D (2006) Slachtoffers bij overstromingen: analyse van een slachtoffermodel aan de hand van de Watersnoodramp van 1953 en overstromingssimulaties. MSc thesis, Delft University

Van der Doef M, Cappendijk P (2006) Veiligheid Nederland in Kaart - modellering en analyse van evacuatie. Report DWW-2006-007. Rijkswaterstaat DWW

Van Manen SE, Brinkhuis M (2005) Quantitative flood risk assessment for polders. Reliab Eng Syst Saf 90(2-3):229-237

Van Zuilekom KM, van Maarsseveen MFAM, van der Doef MR (2005) A decision support system for preventive evacuation of people. In: Proceedings of the first international symposium on geoinformation for disaster management. Delft, the Netherlands, 21-23 March 2005, Springer Verlag

Vrouwenvelder ACWM, Steenhuis CM (1997) Tweede waterkeringen Hoeksche Waard, berekening van het aantal slachtoffers bij verschillende inundatiescenario's. Report TNO 97-CON-R0332

Waarts P (1992) Methode voor de bepaling van het aantal doden als gevolg van inundatie. Report TNO B-91-1099

Watson D, Serrer M, Crookshank N (2001) BC Hydro life safety model-a two dimensional model for estimating dam breach survival probabilities. Draft Technical Report Canadian Hydraulics Centre

WHO (World Health Organization) (2002) Floods: climate change and adaptation strategies for human health. WHO, Copenhagen

Wood M (2007) Wentworth river flood hazard assessment. Environment Waikito Technical Report 2007/16 (draft)

Zhai G, Fukuzono T, Ikeda S (2006) An empirical model of fatalities and injuries due to floods in Japan. J Am Water Resour Assoc 42:863-875 